J Venom Anim Toxins incl Trop Dis, 2019 25: e148118

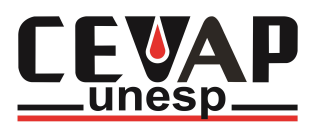

\author{
The Journal of Venomous Animals and \\ Toxins including Tropical Diseases \\ ISSN 1678-9199 \\ Journal homepage www.jvat.org
}

\title{
Scorpion toxins targeting Kv1.3 channels: insights into immunosuppression
}

\author{
Isadora S Oliveira', Isabela G Ferreira', Gabriel M Alexandre-Silva², Felipe A Cerni ${ }^{3}$, Caroline M Cremonez', \\ Eliane C Arantes ${ }^{1}$, Umberto Zottich², Manuela B Pucca ${ }^{2, *}$ \\ ${ }^{1}$ School of Pharmaceutical Sciences of Ribeirão Preto, Department of Physics and Chemistry, University of São Paulo, Ribeirão Preto, SP, Brazil. \\ ${ }^{2}$ Medical School, Federal University of Roraima, Boa Vista, RR, Brazil. \\ ${ }^{3}$ Ribeirão Preto Medical School, Department of Biochemistry and Immunology, University of São Paulo, Ribeirão Preto, SP, Brazil.
}

\section{Article Info \\ Keywords:}

voltage-gated potassium

channels

$\mathrm{Kv} 1.3$

scorpion toxins

$\mathrm{KTx}$

immunosuppression

\begin{abstract}
Scorpion venoms are natural sources of molecules that have, in addition to their toxic function, potential therapeutic applications. In this source the neurotoxins can be found especially those that act on potassium channels. Potassium channels are responsible for maintaining the membrane potential in the excitable cells, especially the voltagedependent potassium channels (Kv), including Kv1.3 channels. These channels (Kv1.3) are expressed by various types of tissues and cells, being part of several physiological processes. However, the major studies of Kv1.3 are performed on T cells due its importance on autoimmune diseases. Scorpion toxins capable of acting on potassium channels (KTx), mainly on Kv1.3 channels, have gained a prominent role for their possible ability to control inflammatory autoimmune diseases. Some of these toxins have already left bench trials and are being evaluated in clinical trials, presenting great therapeutic potential. Thus, scorpion toxins are important natural molecules that should not be overlooked in the treatment of autoimmune and other diseases.
\end{abstract}

\footnotetext{
* Correspondence: 


\section{Background}

Venomous animals are specialized predators that developed high degree of complexity compounds for their own biological purposes [1]. They produced venoms that contain a cocktail of toxins with a great structural and functional diversity [2]. In addition, venom components present diverse characteristics including low-molecular mass, stability, high potency and selectivity for a wide variety of targets in mammalian systems [3, 4].

Nevertheless, one important advantage of venoms is that they can act on many target molecules used for therapeutic intervention $[5,6]$. Therefore, animal venoms are increasingly recognized as a new emerging source of peptide-based therapeutics $[2,7,8]$.

Scorpion venoms are composed of numerous toxins, mostly of peptides and neurotoxins, which can interfere with all biological systems $[9,10]$. Moreover, neurotoxins are known to modify cell membrane ion channels and to cause the release of massive neurotransmitters and cytokines $[10,11]$. In this sense, scorpion venoms have been considered as invaluable resources of ion channel inhibitors and/or modulators, and potassium channel acting toxins (KTx) are one of the most studied [9, 12-14].

Voltage-gated potassium channels $(\mathrm{Kv})$ have received much attention because they are widespread in almost all tissues, besides presenting high expression in mammalian cells. They are involved in the regulation of many physiological processes, including heart rate, neuronal excitability, insulin production, epithelial electrolyte transport, cell proliferation, smooth muscle contraction, neurotransmitter release and immune response [15]. In particular, the voltage-gated potassium channel type 1.3 (Kv1.3) is a well-recognized functional marker and an attractive pharmacological target for treating autoimmune diseases [16]. Thus, based on the interactions between scorpion toxins and potassium channels, a great effort has been employed to find scorpion toxins selectively acting on the Kv1.3 channels [17]. It is important to emphasize that other animals also produce toxins with action on Kv1.3, such as ShK toxin, a potent Kv1.3 inhibitor obtained from Stichodactyla helianthus Caribbean sea anemone venom, and also named as Dalazatide (its synthetic analog) [18]. This first-in-class investigational drug completed phases Ia and Ib of clinical trials and phase IIa is expected to start in this year (2018) [19]. Clinical studies demonstrated that Dalazatide (Kineta Inc.) can decrease skin lesions of psoriasis [20]. Also, this molecule is being study for bringing novel new therapeutics of other autoimmune diseases (e.g. multiple sclerosis and rheumatoid arthritis) [21, 22].

This review will present the current state of art regarding scorpion toxins targeting Kv1.3 channels. Moreover, it will provide details on the Kv1.3 discovery, structure and function focusing on its important role as a target to induce immunosuppression.

\section{Kv1.3 channel discovery and structure}

Kv1.3 currents were firstly recorded in both resting and mitogen stimulated human T lymphocytes in 1984, using patch-clamp technique [23], although in that time the channel did not received the Kv1.3 nomenclature. In the following year, its biophysical properties were also reported. Kv1.3 demonstrated to be a delayed rectifier like voltage-gated potassium channel presenting a slow and very complex mode of inactivation: the lymphocyte $\mathrm{K}^{+}$currents turn on with a sigmoid time course upon the depolarization and, then inactivate almost completely with voltage dependence and kinetics that resemble delayed rectifier $\mathrm{K}^{+}$channel of muscle and nerve [24].

The name Kv1.3 was only introduced in 1991 with a standardized nomenclature [25]. In that study, researchers demonstrated through phylogenetic trees that the channel presents a significant structural homology with the Shaker channel from Drosophila melanogaster. Therefore, the Kv1.3 channel was classified as a mammalian Shaker-related voltagegated potassium channel encoded by the KCNA3 gene, which is found in humans, rats and mice $[25,26]$.

The functional channel is formed by four pore loop-containing a-subunits arranged as a homotetrameric association. Each monomer contains 528 amino acids, six transmembrane segments (S1 through S6) and one pore region formed by the interactions of the four homotetramer to create the walls. In this pore, both the $\mathrm{N}$-terminal and C-terminal domains are located within the cytoplasm [27].

The N-linked glycosylation site is in the external S1-S2 loop, the channel presents two protein kinase $\mathrm{C}$ sites that are located in the S4-S5 linker and a tyrosine kinase site in the N-terminal region. The tripeptide sequence motif $G(Y / F) G$ located in the S5-S6 linker is common to the pore or P loop of these channels and, four of the pore loop domains contribute to the formation of a functional $\mathrm{K}^{+}$conducting pore [27-29].

The transmembrane S4 segment represents the major component of the voltage sensor for this channel, it contains positively charged residues (like lysine or arginine) at almost every third portion of its structure [29].

One interesting approach employed for studying the structure of the Kv1.3 channels is the use of peptides such as scorpion toxins, for mapping the external vestibule of the channel. Based on that, a study was conducted using four scorpion toxins that have the capacity to block the channel (kaliotoxin, charybdotoxin, margatoxin and noxiustoxin). The authors used mutagenesis in combination with quantitative analytical methods and, they could identify several channel residues that interact specifically with toxin residues. These studies revealed the existence of a shallow (4-6 $\AA$ ) and wide ( $35 \AA$ ) saucer-shaped external vestibule with the $\mathrm{K}^{+}$channel signature sequence (GYGD) forming a through as its center $[30,31]$.

One unique feature of the Kv1.3 external vestibule is the presence of a ring of histidine $\sim 9-14 \AA$ in diameter, positioned at the outer entrance of the ion conduction pathway and, none of the so far known Kv channels has a histidine at this position [28].

The external entry to the channel pore consisting of portions of the P-loop and adjacent residues in S5 and S6 segments constitutes possible binding sites for toxins and $\mathrm{K}^{+}$channel blockers. Studies demonstrated that toxins are observed to lock into the channel selectivity filter through a lysine residue in the 
position 27, performing a strong interaction with the channel selectivity filter. Although most of the toxins bind to the Lys27 , this is not a rule, some interact differently with the channel peripheral acidic residues such as Glu-420, Asp-423 and Asp-433, or can even present a different Lys position (Lys-25) [32-34].

\section{Kv1.3 channel role}

Kv1.3 channels are molecules expressed in macrophages, microglia cells, natural killer cells, B and T lymphocytes, osteoclasts, platelets, central nervous system (CNS), prominent in the olfactory bulb and testis [35-38] being able to participate in numerous physiological processes [39]. These channels are important for maintaining the negative membrane potential as they promote intracellular $\mathrm{K}^{+}$efflux as well as help in the influx of extracellular $\mathrm{Ca}^{2+}$ through $\mathrm{Ca}^{2+}$ channels activated by the release of $\mathrm{Ca}^{2+}$ [40-44]. However, this rectifier channel has a characteristic that differentiates it from the other channels from Kv1 family, which is its inactivation for long periods $(\sim 1$ minute or more) after repeated depolarization [45, 46]. Blockage of these channels may bring improvements related to homeostasis regulation, as well as to the immune system [43, 47]. Therefore, mice that have the absence of these channels (knockout animals or $\mathrm{Kv} 1.3 \%$ ) present variation on signaling molecules levels, such as postsynaptic density protein 95 (PSD-95) and tropomyosin receptor kinase $\mathrm{B}(\mathrm{TrKB})$ [48], as well as, there is a decrease of some markers, such as somatostatin and neuropeptide $Y$ interneurons, and an increase of parvalbumin on the cerebral cortex [45]. Moreover, these murine model presents neuroprotection against experimental autoimmune encephalomyelitis (EAE) and increases the levels of interleukin-10 (IL-10) production [49], besides the expression of high levels of forkhead box protein O1 (FoxO1), phosphospecific signal transducer and activator of transcription 5 (pSTAT5), cytotoxic T-lymphocyte-associated protein 4 (CTLA4), erythroid transcription factor (GATA1) and interleukin-2 receptor alpha chain (CD25) [50]. On the other hand, $\mathrm{Kv1} .3^{-/-}$rats show that maximal T-cell responses against autoantigen or repeated tetanus toxoid stimulations require both Kv1.3 and KCa3.1, since knockdown of Kv1.3 rats developed adjuvant-induced arthritis (AIA) in a manner similar to WT rats, indicating that there were no defects in T-cell activation [51].

In addition, it has already been shown that $\mathrm{Kv} 1.3 \%$ mice are able to discriminate odors, as well as, they present high olfactory function, being thus named "super-smellers" [48]. It was also found that these mice were resistant to obesity when induced by a moderately high-fat diet $[52,53]$. They had irregular intake, as well as their metabolic activities, increased locomotion during the dark cycle and behaviors similar to hyperactivity $[48,54]$. Recent studies have shown that the same mice model present exacerbated behaviors related to anxiety, in addition to being inattentive [55].

Although this phenotype causes all these differences, it has been observed that Kv1.3\% animals do not present anomalies in lymphocytes, both in number and type, in T cell proliferation and in thymocyte apoptosis, which may be related to the compensatory increase of the chloride current, maintaining the negative membrane potential [56].

In addition to these animal models, there are several pathological conditions where the dysregulation of Kv1.3 occurs $[39,57,58]$. The list below presents an onset of diseases in which Kv1.3 participates in their pathology (i.e. they are important for cells involved):

- Allergic contact dermatitis: skin disease T-cell mediated, as a delayed hypersensitivity reaction (type IV). In this pathology there is an increase of $\mathrm{T}_{\mathrm{EM}}$ cells T-effector memory lymphocytes $\left(\mathrm{T}_{\mathrm{EM}}\right)[39,59]$;

- Alopecia areata: an autoimmune disease that acts against the hair follicle, which is surrounded by $\mathrm{T}$ and natural killer (NK) cells, and $\mathrm{T}_{\mathrm{EM}}$ cells [39, 60-62];

- Asthma: pathology characterized as chronic inflammation of the airways, caused by infectious or environmental stimuli, leading to reversible bronchoconstriction and presenting an increase of leukocytes [39, 63];

- Atherosclerosis: chronic inflammatory disease in which the innate and adaptive immune responses are activated, forming fatty streaks and the Kv1.3 channels being necessary for the foam cells $[39,64]$;

- Breast cancer: one of the most common types of cancer among females, but there are still controversies regarding Kv1.3 channels, which may be increased or decreased in tumors [39, 65];

- Chronic lymphocytic leukemia: type of chronic leukemia which there is an exacerbated production of B cells, with Kv1.3 channels being very expressed in cell membranes and mitochondria and, when inhibited, leads to cellular apoptosis [39, 66, 67];

- Chronic renal failure: loss of renal function, which occurs with chronic inflammation, with the proliferation of leukocytes in the kidneys that express large amounts of Kv1.3 channels [39, 68];

- Cognitive disabilities: this terminology is given to people who have some deficit of attention, perception, memory, conceptualization, perception, learning disabilities, autism, dyslexia among others related problems [69]. With the inhibition of Kv1.3 channels, an improvement in the symptoms of this disabilities is observed [39];

- Crohn's disease: chronic inflammation of the gastrointestinal system, in which there is an increase of $\mathrm{T}_{\mathrm{EM}}$ cells $[39,70]$;

- Multiple sclerosis: disease mediated by immune system, causing damage to theCNS, such asloss of axonsand demyelination [41,71]. In this pathology there is an increase of $\mathrm{T}_{\mathrm{EM}}$ cells $[18,39]$;

- Muscle sarcomas: type of muscular system cancer, which Kv1.3 channels are expressed in tumors and this expression may be related to its severity $[39,72]$; 
- Obesity: disease associated with human behavior, which the individual presents binge eating and inhibition of Kv1.3 channels led to an increase in insulin sensitivity $[39,73]$.

- Prostate cancer: type of cancer that is closely related to male death and Kv1.3 channels are poorly expressed in these tumors, thus, there is an inverse correlation of this channel expression and the aggressiveness of the cancer [39, 74].

- Psoriasis: a skin disease of chronic and recurrent character, presenting a proliferative increase of the epidermis, as well as its inflammation [75]. In this pathology there is an increase of $\mathrm{T}_{\mathrm{EM}}$ cells [39];

- Rheumatoid arthritis: chronic inflammatory autoimmune disease of the joints and may be accompanied by inflammation in other organs that are not articulated or other chronic symptoms, and, in this pathology, there is an increase of $\mathrm{T}_{\mathrm{EM}}$ cells [39, 76];

- Systemic lupus erythematosus: autoimmune disease, which chronic inflammation is present, as well as innate and adaptive immune responses. In this pathology there are several symptoms and an increase of $\mathrm{T}_{\mathrm{EM}}$ cells $[39,64]$;

- Type I diabetes mellitus: pathological and autoimmune conditions mediated by $\mathrm{T}_{\mathrm{EM}}$ cells. In this pathology the destruction of pancreatic $\beta$-cells occurs [39, 77];

- Type II diabetes mellitus: type of diabetes resistant to insulin and causes hyperglycemia, and when there is inhibition of Kv1.3 channels, an increase in insulin sensitivity occurs [39, 78];

- Ulcerative colitis: chronic inflammation of the gastrointestinal system, being that in the colon and rectum. There is exacerbated activity of T lymphocytes $\left(\mathrm{CD} 4^{+}\right.$and $\left.\mathrm{CD} 8^{+}\right)$, which express Kv1.3 channels [39, 70];

- Vasculitis: chronic inflammation that occurs in the vessel wall, which can affect the lumen as well as cause necrosis and ischemia of the same [79]. In this kind of inflammation, $\mathrm{T}_{\mathrm{EM}}$ cells are involved [39].

Therefore, based on the importance of Kv1.3 in different diseases, the channel has become an important target to novel drug design.

\section{Kv1.3 channel and $T$ cell regulation}

Although many cells express Kv1.3, the most advanced studies with this channel are related to $\mathrm{T}$ cells. The mechanism that makes Kv1.3 channels important to T cells is directly related to intracellular calcium signaling (Fig. 1). Cellular depolarization increases calcium influx, a process that is counterbalanced by Kv1.3 channel opening, which repolarizes the cell and restores calcium through the calcium-release-activated-calcium channel (CRAC). Calcium signaling is also attenuated by the elimination of cytoplasmic cation by $\mathrm{Ca}^{2+}$ ATP-dependent endoplasmic reticulum (SERCA, sarco/endoplasmatic reticulum $\mathrm{Ca}^{2+}$ ATPase) and plasma membrane (PMCA, plasma membrane $\mathrm{Ca}^{2+}$ ATPase) pumps. PMCA pump is activated by increasing the concentration of intracellular $\mathrm{Ca}^{2+}$. Mitochondria play a double role in maintaining signaling via calcium: $(i)$ it can sequester or store large amounts of $\mathrm{Ca}^{2+}$ from the cytoplasm through a single calcium channel (MCU, mitochondrial $\mathrm{Ca}^{2+}$ uniporter); (ii) $\mathrm{MCU}$ can still sequester the $\mathrm{Ca}^{2+}$ ions, inhibiting the negative regulation of CRAC channels [80]. All the calcium influx allows the nuclear factor of activated T cells (NFAT) to translocate to the nucleus and initiate transcription, leading to IL-2 cytokine secretion, a cytokine required for lymphocyte activation and proliferation [81, 82]. Thus, in the absence of sufficient $\mathrm{Ca}^{2+}$ influx via CRAC, T lymphocyte activation, proliferation, and effector functions are completely compromised, as demonstrated by a rare type of human immunodeficiency [83, 84].

All T cell types express Kv1.3, depending on their state of activation and differentiation [71]. According to cellular activation and homing, $\mathrm{T}$ cells can be classified into different phenotypes (Fig. 2): naive T cell, effector T cell and memory $\mathrm{T}$ cell. In addition, memory $\mathrm{T}$ cells may exhibit four different phenotypes: stem memory $\mathrm{T}$ cells $\left(\mathrm{T}_{\mathrm{SCM}}\right)$, central memory $\mathrm{T}$ cells $\left(\mathrm{T}_{\mathrm{CM}}\right), \mathrm{T}_{\mathrm{EM}}$ and tissue resident memory $\mathrm{T}$ cells $\left(\mathrm{T}_{\mathrm{RM}}\right)$ [85]. However, Kv1.3 channels have a greater expression and, consequently, a greater importance on effector memory $\mathrm{T}$ cells or $\mathrm{T}_{\mathrm{EM}}$. Naïve cells and $\mathrm{T}_{\mathrm{CM}}\left(\mathrm{CD} 4^{+}\right.$and $\left.\mathrm{CD} 8^{+}\right)$express 400 to $500 \mathrm{Kv1.3/cell.} \mathrm{In} \mathrm{contrast,} \mathrm{T}_{\mathrm{EM}}$ cells express 1,500 Kv1.3/cell. In relation to the other potassium channel expressed in $\mathrm{T}$ cells, the potassium channel activated by calcium (KCa3.1), different numbers are observed: naive $\mathrm{T}_{\text {and }} \mathrm{T}_{\mathrm{CM}}$ : 200 to $500 \mathrm{KCa} 3.1 / \mathrm{cell}$; $\left.\mathrm{T}_{\mathrm{EM}}: 10 \mathrm{KCa} 3.1 / \mathrm{cell}\right)[41,86,87]$. Thus, although both potassium channels (Kv1.3 and KCa3.1) are responsible for intracellular potassium signaling, differences in channel/cell numbers justify the importance of the Kv1.3 channel for $\mathrm{T}_{\mathrm{EM}}$ cells [88].

Knowing that $\mathrm{T}_{\mathrm{EM}}$ cells are responsible for the development of autoimmune diseases, the studies with modulation of Kv1.3 channels have mightily intensified aiming new therapies using this receptor as target. Furthermore, because Kv1.3 channels are expressed in higher amounts only in $\mathrm{T}_{\mathrm{EM}}$ cells, this targeted therapy would not impair the naïve or $\mathrm{T}_{\mathrm{CM}}$ responses $[41,89,90]$.

\section{Kv1.3 channel scorpion toxins' blockers}

Some scorpion venom toxins have the property of interacting specifically with $\mathrm{K}^{+}$channels and are named as KTx [21, 91]. These toxins comprise a group of peptides having 23 to 64 amino acid residues, and may contain from three to four disulfide bonds [92]. According to their structure, amino acid sequence and disulfide bonds, these toxins can be classified, such as $\alpha, \beta, \varepsilon$, $\kappa, \gamma$ and $\lambda$-KTx [91-94].

Kumenskov and colleagues created a database that presents toxins that interact with $\mathrm{K}$ channels (kaliumdb.org). In that database there are 319 animal toxins, which, 174 are derived from scorpion venom. However, only 81 toxins are capable of interacting with the Kv1.3 channels (Table1) [95]. Although they present different affinities, we can define their potential to be considered a bona fide blocker by comparing them to the potency of Dalazatide, which presents an $\mathrm{EC}_{50}<100 \mathrm{pM}$ [96]. 


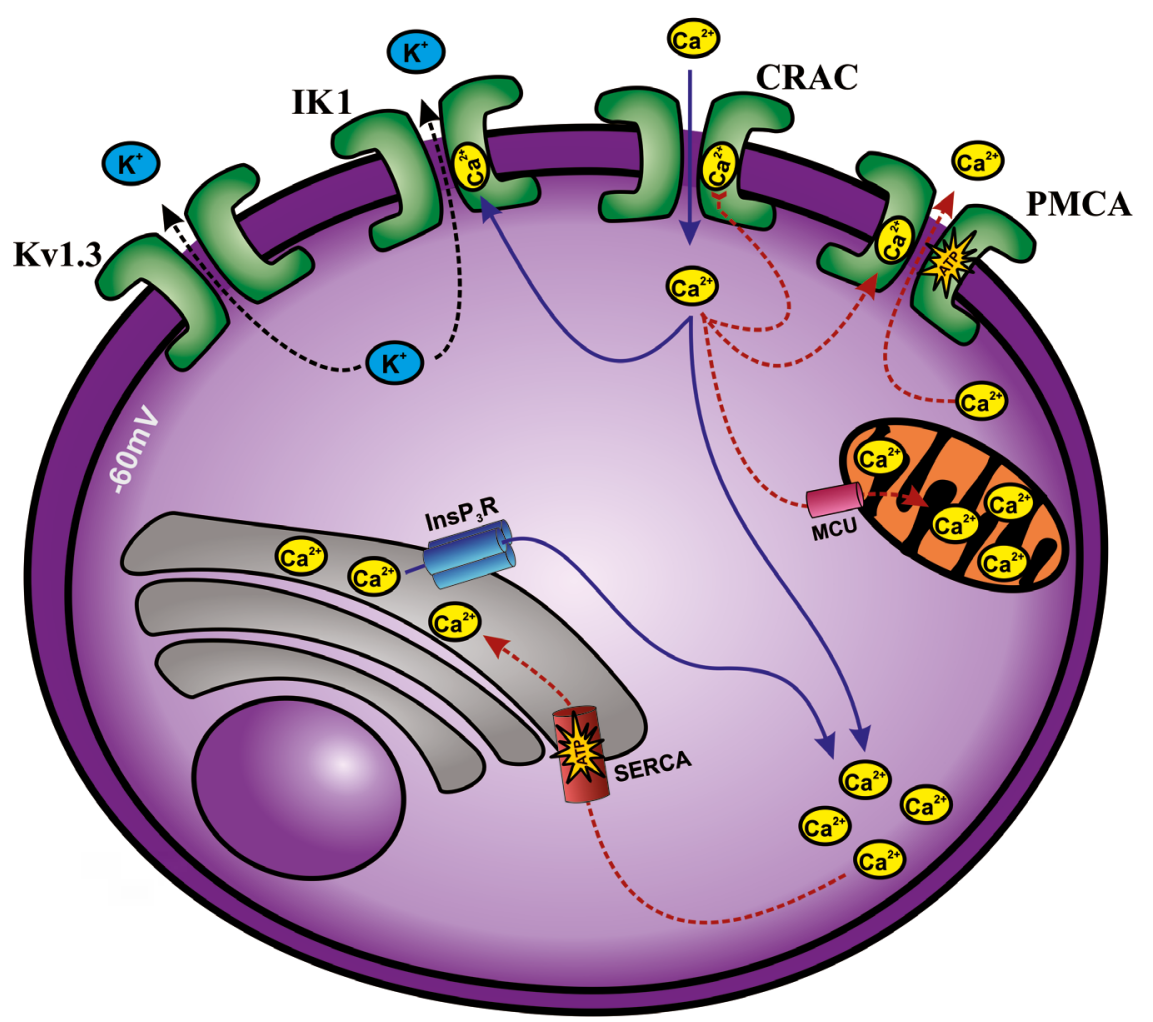

Figure 1. Kv1.3 and $\mathbf{C a}^{+2}$ signaling in $\mathbf{T}$ cells. Depolarization of the $\mathrm{T}$ cells (about $-60 \mathrm{mV}$ ) reduces the driving force for $\mathrm{Ca}^{+2}$ entry through calcium-releaseactivated calcium (CRAC) channels, which is counteracted by the opening of Kv1.3 channels. On the other hand, IK1 (intermediate conductance calcium-activated potassium channel protein 1) channels open in response to $\mathrm{Ca}^{+2}$ influx and increased intracellular $\mathrm{Ca}^{+2}$ concentration. Ca ${ }^{+2}$ are diminished by the ATP-dependent $\mathrm{Ca}^{+2}$ pumps - SERCA (sarco/endoplasmic reticulum $\mathrm{Ca}^{+2}$ ATPase) and PMCA (plasma membrane $\mathrm{Ca}^{+2}$ ATPase). PMCA is activated by increases in intracellular $\mathrm{Ca}^{+2}$ signals. Mitochondria can take up and store large amounts of $\mathrm{Ca}^{+2}$ from the cytoplasm using MCU (mitochondrial $\mathrm{Ca}^{+2}$ uniporter) or it can sequester $\mathrm{Ca}^{+2}$ locally. linositol-1,4,5-trisphosphate receptor (InsP3R) can also senses $\mathrm{Ca}^{+2}$ waves and enhance intracellular $\mathrm{Ca}^{+2}$ levels. Blue solid lines represent the pathways that enhance intracellular $\mathrm{Ca}^{+2}$ levels. Red dashed lines represent the pathways that reduce intracellular $\mathrm{Ca}^{+2}$ levels. Black dashed line represents $\mathrm{K}^{+}$efflux.

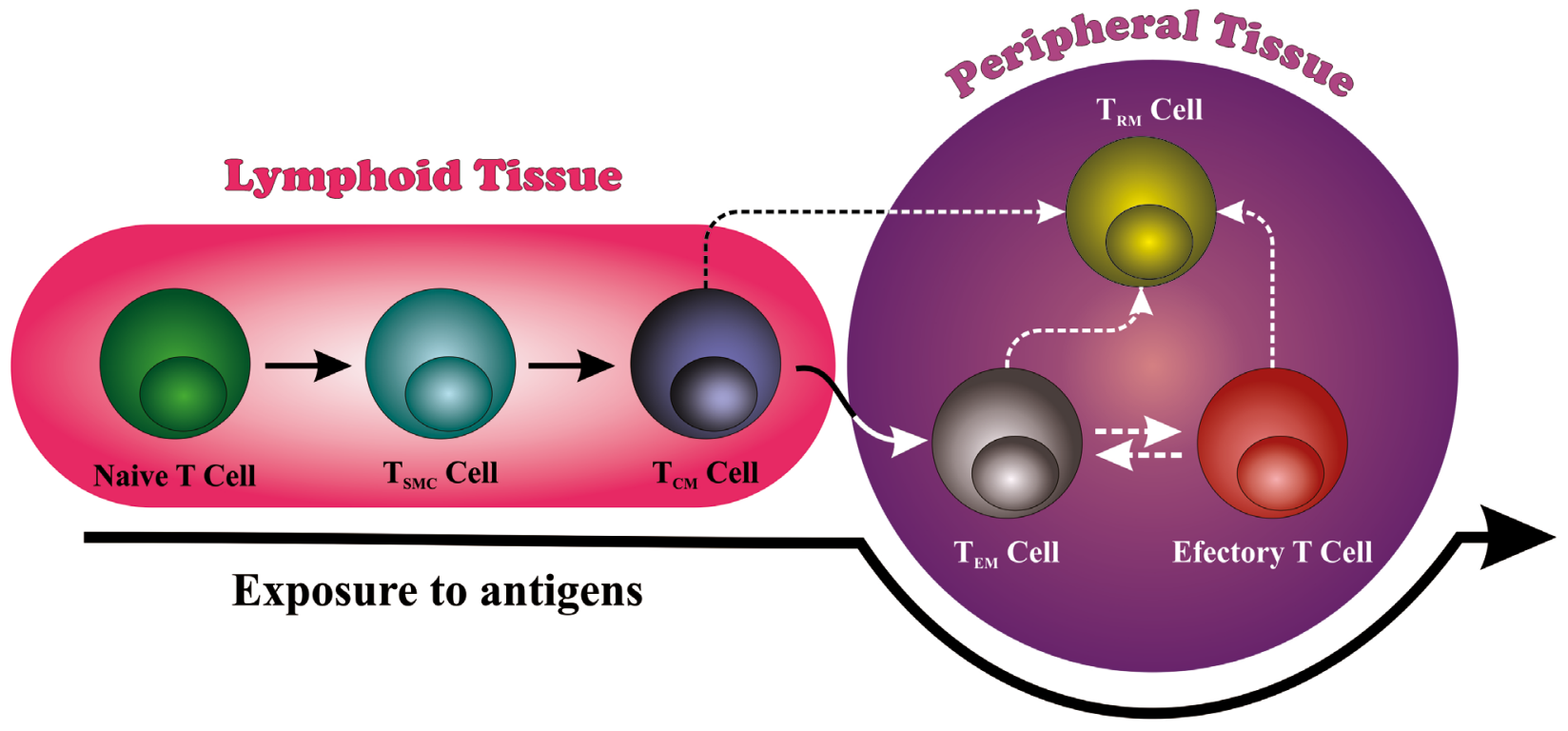

Figure 2. T cell subsets generation according to cellular activation and homing. T cells can be differentiated in different populations according to antigen exposure. Moreover, these $T$ cells can be localized in different tissues (lymphoid and peripheral tissues). $T_{\text {scm. }}$ stem memory $T_{\text {cell. }} T_{\text {cM }}$ central memory $T$ cell. $T_{E M:}$ effector memory $T$ cell. $T_{R M}$ tissue resident memory $T$ cell. Solid lines represent elucidated mechanism of differentiation. Dashed lines represent mechanisms still unclear. 
Table 1. Scorpion toxins targeting $K_{v} 1.3$ channels.

\begin{tabular}{|c|c|c|c|c|c|c|}
\hline Toxin & Classification & Scorpion specie & Modification & Assay/Cell type & $\begin{array}{c}\mathrm{Kd} / \mathrm{IC50} / \\
\mathrm{EC50}(\mathrm{nM})\end{array}$ & Reference \\
\hline Aam-KTX & a-KTx 3.12 & $\begin{array}{l}\text { Androctonus } \\
\text { amoreuxi }\end{array}$ & Kaliotoxin analog & $\begin{array}{l}\text { Electrophysiological experiments } \\
\text { with Xenopus leaves oocytes }\end{array}$ & 1.1 & {$[97]$} \\
\hline ADWX-1* & $\mathrm{a}-\mathrm{KTx}$ & B. martensii & Recombinant & $\begin{array}{l}\text { Electrophysiological experiments } \\
\text { with HEK } 293 \text { cells }\end{array}$ & 0.001 & {$[98]$} \\
\hline $\mathrm{AgTX}-1$ & $\mathrm{a}-\mathrm{KT} \times 3.4$ & $\begin{array}{l}\text { L. quinuqestriatus } \\
\text { var. hebraeus }\end{array}$ & & $\begin{array}{l}\text { Electrophysiological experiments } \\
\text { with HEK } 293 \text { cells }\end{array}$ & 1.7 & [99] \\
\hline $\mathrm{AgTX}-2$ & $\mathrm{a}-\mathrm{KT} \times 3.2$ & $\begin{array}{l}\text { L. quinuqestriatus } \\
\text { var. hebraeus }\end{array}$ & & $\begin{array}{l}\text { Electrophysiological experiments } \\
\text { with Xenopus oocytes/ In vitro } \\
\text { L929 mouse fibroblast and Human } \\
\text { T-lymphocytes }\end{array}$ & 0.004 & {$[99,100]$} \\
\hline Anuroctoxin* & $\mathrm{a}-\mathrm{KT} \times 6.12$ & $\begin{array}{l}\text { Anuroctonus } \\
\text { phaiodactylus }\end{array}$ & & $\begin{array}{l}\text { Electrophysiological experiments } \\
\text { with human peripheral } \mathrm{T} \\
\text { lymphocytes }\end{array}$ & 0.73 & {$[101]$} \\
\hline BmK86* & $\mathrm{a}-\mathrm{KT} \times 26.1$ & $\begin{array}{l}\text { Mesobuthus } \\
\text { martensii Karsch }\end{array}$ & & $\begin{array}{l}\text { Electrophysiological experiments } \\
\text { with COS7 cells cells }\end{array}$ & 150 & {$[102]$} \\
\hline BmKTT-1 & $\delta-K T \times 2.4$ & Buthus martensii & Recombinant & $\begin{array}{l}\text { Electrophysiological experiments } \\
\text { with HEK } 293 \text { cells }\end{array}$ & 129.7 & {$[103]$} \\
\hline BmKTT-2 & $\delta-K T \times 3.1$ & Buthus martensii & Recombinant & $\begin{array}{l}\text { Electrophysiological experiments } \\
\text { with HEK } 293 \text { cells }\end{array}$ & 371.3 & {$[103]$} \\
\hline BmKTT-3 & $\delta-K T \times 1.2$ & Buthus martensii & Recombinant & $\begin{array}{l}\text { Electrophysiological experiments } \\
\text { with HEK } 293 \text { cells }\end{array}$ & $>1000$ & [103] \\
\hline BmKTX* & $\mathrm{a}-\mathrm{KTx}$ & B. martensi Karsch & & $\begin{array}{l}\text { Electrophysiological experiments } \\
\text { with HEK } 293 \text { cells }\end{array}$ & 0.09 & {$[104]$} \\
\hline BmP01 & $\mathrm{a}-\mathrm{KT} \times 8.2$ & $\begin{array}{c}\text { Mesobuthus } \\
\text { martensii }\end{array}$ & & $\begin{array}{l}\text { Electrophysiological experiments } \\
\text { with Xenopus leaves oocytes }\end{array}$ & 133.72 & {$[105]$} \\
\hline $\mathrm{BmP02}$ & $\mathrm{a}-\mathrm{KT} \times 9.1$ & $\begin{array}{l}\text { Mesobuthus } \\
\text { martensii }\end{array}$ & & $\begin{array}{l}\text { Electrophysiological experiments } \\
\text { with Xenopus oocytes }\end{array}$ & 7 & {$[106]$} \\
\hline $\mathrm{BmP03}$ & $\mathrm{a}-\mathrm{KT} \times 9.2$ & $\begin{array}{l}\text { Mesobuthus } \\
\text { martensii }\end{array}$ & & $\begin{array}{l}\text { Electrophysiological experiments } \\
\text { with Xenopus oocytes }\end{array}$ & 85.4 & {$[106]$} \\
\hline $\mathrm{BmTX1}$ & $\mathrm{a}-\mathrm{KT} \times 1.5$ & Buthus martensii & & $\begin{array}{l}\text { Electrophysiological experiments } \\
\text { with Xenopus oocytes }\end{array}$ & 1.5 & {$[107]$} \\
\hline $\mathrm{BmTX2}$ & $\mathrm{a}-\mathrm{KT} \times 1.6$ & Buthus martensii & & $\begin{array}{l}\text { Electrophysiological experiments } \\
\text { with Xenopus oocytes }\end{array}$ & 1.6 & {$[107]$} \\
\hline BoiTx1 & $\mathrm{a}-\mathrm{KT} \times 3.10$ & $\begin{array}{c}\text { Buthus occitanus } \\
\text { israelis }\end{array}$ & & $\begin{array}{l}\text { Electrophysiological experiments } \\
\text { with Xenopus leaves oocytes }\end{array}$ & 3.5 & {$[108]$} \\
\hline BuTX & $\mathrm{a}-\mathrm{KT} \times 12.2$ & Tityus trivittatus & & $\begin{array}{l}\text { Electrophysiological experiments } \\
\text { with Xenopus leaves oocytes }\end{array}$ & 0.55 & {$[34,109,110]$} \\
\hline $\mathrm{Ce}{ }^{*}$ & $\mathrm{a}-\mathrm{KT} \times 2.8$ & $\begin{array}{l}\text { Centruroides } \\
\text { elegans }\end{array}$ & & $\begin{array}{l}\text { Electrophysiological experiments } \\
\text { with human T lymphocytes }\end{array}$ & 0.7 & {$[111]$} \\
\hline $\mathrm{Ce} 2 *$ & $\mathrm{a}-\mathrm{KT} \times 2.9$ & $\begin{array}{l}\text { Centruroides } \\
\text { elegans }\end{array}$ & & $\begin{array}{l}\text { Electrophysiological experiments } \\
\text { with human T lymphocytes }\end{array}$ & 0.25 & {$[111]$} \\
\hline $\mathrm{Ce} 3$ & $\mathrm{a}-\mathrm{KT} \times 2.10$ & $\begin{array}{l}\text { Centruroides } \\
\text { elegans }\end{array}$ & & $\begin{array}{l}\text { Electrophysiological experiments } \\
\text { with human T lymphocytes }\end{array}$ & 366 & {$[111]$} \\
\hline Ce4* & $\mathrm{a}-\mathrm{KT} \times 2.11$ & $\begin{array}{l}\text { Centruroides } \\
\text { elegans }\end{array}$ & & $\begin{array}{l}\text { Electrophysiological experiments } \\
\text { with human T lymphocytes }\end{array}$ & 0.98 & {$[111]$} \\
\hline $\mathrm{Ce} 5$ & $\mathrm{a}-\mathrm{KT} \times 2.12$ & $\begin{array}{l}\text { Centruroides } \\
\text { elegans }\end{array}$ & & $\begin{array}{l}\text { Electrophysiological experiments } \\
\text { with human T lymphocytes }\end{array}$ & 69 & {$[111]$} \\
\hline Charybdotoxin & $\mathrm{a}-\mathrm{KT} \times 1.1$ & $\begin{array}{l}\text { L. quinquestriatus } \\
\text { hebraeus }\end{array}$ & & $\begin{array}{l}\text { Electrophysiological experiments } \\
\text { with mammalian cell line that } \\
\text { presents cloned Kv1.3 channels }\end{array}$ & 2.6 & {$[112]$} \\
\hline CoTx1 & $\mathrm{a}-\mathrm{KT} \times 10.1$ & Centruroides noxius & & $\begin{array}{l}\text { Electrophysiological experiments } \\
\text { with Rat brain synaptosomes }\end{array}$ & 5.3 & {$[113]$} \\
\hline Css20* & $\mathrm{a}-\mathrm{KT} \times 2.13$ & $\begin{array}{l}\text { Centruroides } \\
\text { suffusus suffuses }\end{array}$ & & $\begin{array}{l}\text { Electrophysiological experiments } \\
\text { with human peripheral T } \\
\text { lymphocytes }\end{array}$ & 7.2 & {$[114]$} \\
\hline
\end{tabular}


Table 1. Cont.

\begin{tabular}{|c|c|c|c|c|c|c|}
\hline Toxin & Classification & Scorpion specie & Modification & Assay/Cell type & $\begin{array}{l}\mathrm{Kd} / \mathrm{IC50} / \\
\mathrm{EC50}(\mathrm{nM})\end{array}$ & Reference \\
\hline Ctri18* & a-KTx 15 & Chaerilus tricostatus & Recombinant & $\begin{array}{l}\text { Electrophysiological experiments } \\
\text { with HEK } 293 \text { cells }\end{array}$ & ND & {$[115]$} \\
\hline Ctri9577* & $\mathrm{a}-\mathrm{K} T \times 15.10$ & Chaerilus tricostatus & & $\begin{array}{l}\text { Electrophysiological experiments } \\
\text { with HEK } 293 \text { cells }\end{array}$ & 0.49 & [116] \\
\hline Ctry2908* & $\mathrm{a}-\mathrm{KT} \times 15$ & Chaerilus tryznai & Recombinant & $\begin{array}{l}\text { Electrophysiological experiments } \\
\text { with HEK } 293 \text { cells }\end{array}$ & ND & [115] \\
\hline Ctry68* & $\mathrm{a}-\mathrm{KT} \times 15$ & Chaerilus tryznai & Recombinant & $\begin{array}{l}\text { Electrophysiological experiments } \\
\text { with HEK } 293 \text { cells }\end{array}$ & ND & [115] \\
\hline Hemitoxin & $\mathrm{a}-\mathrm{KT} \times 6.15$ & $\begin{array}{l}\text { Hemiscorpius } \\
\text { lepturus }\end{array}$ & & $\begin{array}{l}\text { Electrophysiological experiments } \\
\text { with Xenopus oocytes }\end{array}$ & 2 & [117] \\
\hline Hetlaxin* & Data not shown & $\begin{array}{l}\text { Heterometrus } \\
\text { laoticus }\end{array}$ & & $\begin{array}{l}\text { Competitive binding experiments } \\
\text { with chimeric KcsA-Kv1.3 }\end{array}$ & 410 & [118] \\
\hline $\mathrm{HeT} \times 204$ & $\mathrm{k}-\mathrm{KT} \times 2.8$ & $\begin{array}{l}\text { Heterometrus } \\
\text { petersii }\end{array}$ & & $\begin{array}{l}\text { Electrophysiological experiments } \\
\text { with HEK293 cells }\end{array}$ & ND & [119] \\
\hline $\mathrm{Hg} 1 *$ & $\delta-K T \times 1.1$ & Hadrurus gertschi & Recombinant & $\begin{array}{l}\text { Electrophysiological experiments } \\
\text { with HEK } 293 \text { cells }\end{array}$ & 6.2 & $\begin{array}{c}{[103,120,} \\
121]\end{array}$ \\
\hline Hongotoxin & $\mathrm{a}-\mathrm{KT} \times 2.5$ & $\begin{array}{l}\text { Centruroides } \\
\text { limbatus }\end{array}$ & & $\begin{array}{l}\text { Inhibition of }{ }^{86} \mathrm{Rb}^{+} \text {flux in HEK293 } \\
\text { cells }\end{array}$ & 0.086 & [122] \\
\hline $\mathrm{HsT} \times 1^{\#}$ & $\mathrm{a}-\mathrm{KT} \times 6.3$ & $\begin{array}{l}\text { Heterometrus } \\
\text { spinnifer }\end{array}$ & & $\begin{array}{l}\text { Electrophysiological experiments } \\
\text { with L929 cells/ In vivo assay using } \\
\text { DTH reaction, Lewis rat / In vivo } \\
\text { assay using Pristane-induced } \\
\text { arthritis model, Dark Agouti rats }\end{array}$ & 0.011 & {$[123,124]$} \\
\hline $\mathrm{HsT} \times 1[\mathrm{R} 14 \mathrm{~A}]^{*}$ & Data not shown & $\begin{array}{l}\text { Heterometrus } \\
\text { spinnifer }\end{array}$ & Synthetic peptide & $\begin{array}{l}\text { Electrophysiological experiments } \\
\text { with L929 cells }\end{array}$ & 0.027 & [124] \\
\hline $\operatorname{ImKtx} 1 *$ & $\lambda-\mathrm{KT} \times 1.1$ & $\begin{array}{l}\text { Isometrus } \\
\text { maculates }\end{array}$ & & $\begin{array}{l}\text { Electrophysiological experiments } \\
\text { with HEK293 cells }\end{array}$ & 1700 & [125] \\
\hline ImKTX88*\# & $\mathrm{a}-\mathrm{K} T \mathrm{x}$ & $\begin{array}{l}\text { Isometrus } \\
\text { maculates }\end{array}$ & Recombinant & $\begin{array}{l}\text { Electrophysiological experiments } \\
\text { with HEK } 293 \text { cells/ In vivo } \\
\text { experimental autoimmune } \\
\text { encephalomyelitis mice }\end{array}$ & 0.091 & {$[126,127]$} \\
\hline J123* & a-KTx 11.5 & $\begin{array}{l}\text { Buthus martensii } \\
\text { Karsch }\end{array}$ & & $\begin{array}{l}\text { Electrophysiological experiments } \\
\text { with HEK } 293 \text { cells }\end{array}$ & 0.79 & [128] \\
\hline Kaliotoxin" & $\mathrm{a}-\mathrm{KT} \times 3.1$ & $\begin{array}{l}\text { Androctonus } \\
\text { mauretanicus } \\
\text { mauretanicus }\end{array}$ & & $\begin{array}{l}\text { Electrophysiological experiments } \\
\text { with mammalian cell line that } \\
\text { presents cloned } \mathrm{Kv} 1.3 \text { channels/ In } \\
\text { vivo rat periodontal disease model }\end{array}$ & 0.65 & {$[112,129]$} \\
\hline Kbot1 & $\mathrm{a}-\mathrm{KT} \times 9.5$ & $\begin{array}{l}\text { Buthus occitanus } \\
\text { tunetanus }\end{array}$ & & $\begin{array}{l}\text { Electrophysiological experiments } \\
\text { with Xenopus oocytes }\end{array}$ & 15 & [130] \\
\hline k-Hefutoxin1 & к-KTx 1.1 & $\begin{array}{l}\text { Heterometrus } \\
\text { fulvipes }\end{array}$ & & $\begin{array}{l}\text { Electrophysiological experiments } \\
\text { with Xenopus leaves oocytes }\end{array}$ & 40000 & [131] \\
\hline LmKTT-1a & $\delta-K T \times 2.1$ & Lychas mucronatus & Recombinant & $\begin{array}{l}\text { Electrophysiological experiments } \\
\text { with HEK } 293 \text { cells }\end{array}$ & $>1000$ & {$[103,132]$} \\
\hline LmKTT-1b & $\delta-K T \times 2.2$ & Lychas mucronatus & Recombinant & $\begin{array}{l}\text { Electrophysiological experiments } \\
\text { with HEK } 293 \text { cells }\end{array}$ & $>1000$ & {$[103,132]$} \\
\hline LmKTT-1c & $\delta-K T \times 2.3$ & Lychas mucronatus & Recombinant & $\begin{array}{l}\text { Electrophysiological experiments } \\
\text { with HEK } 293 \text { cells }\end{array}$ & $>1000$ & [103] \\
\hline LmKTx10* & $\mathrm{a}-\mathrm{KT} \times 12.5$ & Lychas mucronatus & & $\begin{array}{l}\text { Electrophysiological experiments } \\
\text { with HEK293 cells }\end{array}$ & 28 & [133] \\
\hline LmKTx8* & $\mathrm{a}-\mathrm{KT} \mathrm{T} 11.4$ & Lychas mucronatus & & $\begin{array}{l}\text { Electrophysiological experiments } \\
\text { with COS7 cells }\end{array}$ & 26.4 & [134] \\
\hline Margatoxin*\# & $\mathrm{a}-\mathrm{KT} \times 2.2$ & $\begin{array}{l}\text { Centruroides } \\
\text { margaritatus }\end{array}$ & & $\begin{array}{l}\text { Electrophysiological experiments } \\
\text { with human peripheral T } \\
\text { lymphocytes/ In vitro human lung } \\
\text { cancer A549/ In vivo-xenograft } \\
\text { assay, nude mice }\end{array}$ & $\sim 0.030$ & {$[135,136]$} \\
\hline
\end{tabular}


Table 1 Cont.

\begin{tabular}{|c|c|c|c|c|c|c|}
\hline Toxin & Classification & Scorpion specie & Modification & Assay/Cell type & $\begin{array}{l}\mathrm{Kd} / \mathrm{IC50} / \\
\mathrm{EC50}(\mathrm{nM})\end{array}$ & Reference \\
\hline Maurotoxin & $\mathrm{a}-\mathrm{KT} \times 6.2$ & $\begin{array}{l}\text { Scorpio maurus } \\
\text { palmatus }\end{array}$ & & $\begin{array}{l}\text { Electrophysiological experiments } \\
\text { with L929 cells }\end{array}$ & 155 & [123] \\
\hline MegKTx3 & $\mathrm{a}-\mathrm{KT} \times 16.7$ & $\begin{array}{l}\text { Mesobuthus } \\
\text { gibbosus }\end{array}$ & & $\begin{array}{l}\text { Electrophysiological experiments } \\
\text { with Xenopus leaves oocytes }\end{array}$ & 118.3 & [137] \\
\hline MeuKTx-1* & $\mathrm{a}-\mathrm{KT} \times 8.6$ & Mesobuthus eupeus & & $\begin{array}{l}\text { Electrophysiological experiments } \\
\text { with Xenopus leaves oocytes }\end{array}$ & 2.36 & [105] \\
\hline MeuKTx-3 & $\mathrm{a}-\mathrm{KT} \times 3.13$ & Mesobuthus eupeus & & $\begin{array}{l}\text { Electrophysiological experiments } \\
\text { with Xenopus oocytes }\end{array}$ & 0.171 & [138] \\
\hline MeuKTx-4* & $\mathrm{a}-\mathrm{KT} \times 16.4$ & Mesobuthus eupeus & & $\begin{array}{l}\text { Electrophysiological experiments } \\
\text { with Xenopus leaves oocytes }\end{array}$ & ND & [139] \\
\hline MTX-HsTX1 & $\mathrm{a}-\mathrm{KT} \times \mathrm{x}$ & $\begin{array}{l}\text { Scorpio maurus } \\
\text { palmatus and } \\
\text { Heterometrus } \\
\text { spinnifer }\end{array}$ & $\begin{array}{l}\text { Chimera using } \\
\text { maurotoxin and } \\
\text { HsTX1 toxins }\end{array}$ & $\begin{array}{l}\text { Electrophysiological experiments } \\
\text { with L929 cells }\end{array}$ & 4 & [123] \\
\hline Noxiustoxin & $\mathrm{a}-\mathrm{KT} \times 2.1$ & Centruroides noxius & & $\begin{array}{l}\text { Electrophysiological experiments } \\
\text { with mammalian cell line that } \\
\text { presents cloned Kv1.3 channels }\end{array}$ & 1 & [112] \\
\hline OcyKTx2 & $\mathrm{a}-\mathrm{K} T \times 6.17$ & $\begin{array}{l}\text { Opisthacanthus } \\
\text { cayaporum }\end{array}$ & & $\begin{array}{l}\text { Electrophysiological experiments } \\
\text { with human peripheral T } \\
\text { lymphocytes }\end{array}$ & 17.7 & [140] \\
\hline OdK2* & $\mathrm{a}-\mathrm{KT} \times 3.1$ & $\begin{array}{l}\text { Odonthobuthus } \\
\text { doriae }\end{array}$ & & $\begin{array}{l}\text { Electrophysiological experiments } \\
\text { with Xenopus leaves oocytes }\end{array}$ & 7.2 & [141] \\
\hline OmTx1 & $\mathrm{K}-\mathrm{KT} \times 2.1$ & $\begin{array}{l}\text { Opisthacanthus } \\
\text { madagascariensis }\end{array}$ & & $\begin{array}{l}\text { Electrophysiological experiments } \\
\text { with Xenopus leaves oocytes }\end{array}$ & ND & {$[142]$} \\
\hline OmTx2 & к-KTx 2.2 & $\begin{array}{l}\text { Opisthacanthus } \\
\text { madagascariensis }\end{array}$ & & $\begin{array}{l}\text { Electrophysiological experiments } \\
\text { with Xenopus leaves oocytes }\end{array}$ & ND & [142] \\
\hline OmTx3 & к-KTx 2.3 & $\begin{array}{l}\text { Opisthacanthus } \\
\text { madagascariensis }\end{array}$ & & $\begin{array}{l}\text { Electrophysiological experiments } \\
\text { with Xenopus leaves oocytes }\end{array}$ & ND & {$[142]$} \\
\hline Osk1 $1^{\#}$ & a-KTx 3.7 & $\begin{array}{l}\text { Orthochirus } \\
\text { scrobiculosus }\end{array}$ & & $\begin{array}{l}\text { Electrophysiological experiments } \\
\text { with L929 and murine } \\
\text { erythroleukaemia cells/ In vivo } \\
\text { neurotoxicity assay, C57/BL6 mice }\end{array}$ & 0.014 & [143] \\
\hline PBT 1 & $\mathrm{a}-\mathrm{KT} \times 11.1$ & Parabuthus villosus & & $\begin{array}{l}\text { Electrophysiological experiments } \\
\text { with Xenopus oocytes }\end{array}$ & ND & [144] \\
\hline PBT 3 & $\mathrm{a}-\mathrm{K} T \times 1.10$ & $\begin{array}{l}\text { Parabuthus } \\
\text { transvaalicus }\end{array}$ & & $\begin{array}{l}\text { Electrophysiological experiments } \\
\text { with Xenopus leaves oocytes }\end{array}$ & 492 & [144] \\
\hline PEG-HsTX1[R14A]* & Data not shown & $\begin{array}{l}\text { Heterometrus } \\
\text { spinnifer }\end{array}$ & $\begin{array}{l}\text { PEGylated } \\
\text { molecule }\end{array}$ & $\begin{array}{l}\text { Electrophysiological experiments } \\
\text { with L929 cells }\end{array}$ & 35.9 & [124] \\
\hline Pi1* & $\mathrm{a}-\mathrm{KT} \times 6.1$ & Pandinus imperator & & $\begin{array}{l}\text { Electrophysiological experiments } \\
\text { with human lymphocytes }\end{array}$ & 9.7 & [145] \\
\hline $\mathrm{Pi} 2 *$ & $\mathrm{a}-\mathrm{KT} \times \mathrm{x} .1$ & Pandinus imperator & & $\begin{array}{l}\text { Electrophysiological experiments } \\
\text { with human lymphocytes }\end{array}$ & 0.05 & [145] \\
\hline Pi3* & $\mathrm{a}-\mathrm{KT} \times 7.2$ & Pandinus imperator & & $\begin{array}{l}\text { Electrophysiological experiments } \\
\text { with human lymphocytes }\end{array}$ & 0.5 & [145] \\
\hline StKTx23* & $\mathrm{a}-\mathrm{K} T \times 30.1$ & $\begin{array}{l}\text { Scorpiops } \\
\text { margerisonae }\end{array}$ & & $\begin{array}{l}\text { Electrophysiological experiments } \\
\text { with HEK } 293 \text { cells }\end{array}$ & ND & [119] \\
\hline Tc30 & $\mathrm{a}-\mathrm{KT} \times 4.4$ & Tityus cambridgei & & $\begin{array}{l}\text { Electrophysiological experiments } \\
\text { with T lymphocytes }\end{array}$ & 16 & [146] \\
\hline Tc32 & $\mathrm{a}-\mathrm{KT} \times 18.1$ & Tityus cambridgei & & $\begin{array}{l}\text { Electrophysiological experiments } \\
\text { with T lymphocytes }\end{array}$ & 10 & [146] \\
\hline Ts6" & $\mathrm{a}-\mathrm{KT} \times 12.1$ & Tityus serrulatus & & $\begin{array}{l}\text { Electrophysiological experiments } \\
\text { with Xenopus leaves oocytes / In } \\
\text { vivo assay using DTH reaction, } \\
\text { BALB/c mice }\end{array}$ & 0.55 & {$[34]$} \\
\hline Ts7 & $\mathrm{a}-\mathrm{KT} \times 4.1$ & Tityus serrulatus & & $\begin{array}{l}\text { Electrophysiological experiments } \\
\text { with Xenopus leaves oocytes }\end{array}$ & ND & [34] \\
\hline
\end{tabular}


Table 1 Cont.

\begin{tabular}{|c|c|c|c|c|c|c|}
\hline Toxin & Classification & Scorpion specie & Modification & Assay/Cell type & $\begin{array}{c}\mathrm{Kd} / \mathrm{IC50} / \\
\mathrm{EC50}(\mathrm{nM})\end{array}$ & Reference \\
\hline Ts15\# & $\mathrm{a}-\mathrm{K} T \times 21.1$ & Tityus serrulatus & & $\begin{array}{l}\text { Electrophysiological experiments } \\
\text { with Xenopus leaves oocytes / In } \\
\text { vivo assay using DTH reaction, } \\
\text { BALB/c mice }\end{array}$ & $\begin{array}{c}508 \\
1073\end{array}$ & {$[147,148]$} \\
\hline Tst26* & $\mathrm{a}-\mathrm{KT} \times 4.6$ & Tityus stigmurus & & $\begin{array}{l}\text { Electrophysiological experiments } \\
\text { with human peripheral T } \\
\text { lymphocytes }\end{array}$ & 10.7 & [149] \\
\hline Tt28 & $\mathrm{a}-\mathrm{KT} \times 20.1$ & Tityus trivittatus & & $\begin{array}{l}\text { Electrophysiological experiments } \\
\text { with Xenopus leaves oocytes }\end{array}$ & 7.9 & [150] \\
\hline Urotoxin & $\mathrm{a}-\mathrm{K} T \times 6.21$ & $\begin{array}{l}\text { Urodacus } \\
\text { yaschenkoi }\end{array}$ & & $\begin{array}{l}\text { Electrophysiological experiments } \\
\text { with human peripheral T } \\
\text { lymphocytes }\end{array}$ & 91 & [151] \\
\hline Vm23* & $\mathrm{a}-\mathrm{KT} \times 23.2$ & $\begin{array}{l}\text { Vaejovis mexicanus } \\
\text { smithi }\end{array}$ & & $\begin{array}{l}\text { Electrophysiological experiments } \\
\text { with human peripheral T } \\
\text { lymphocytes }\end{array}$ & 10 & [152] \\
\hline Vm24*\# & $\mathrm{a}-\mathrm{KT} \times 23.1$ & $\begin{array}{l}\text { Vaejovis mexicanus } \\
\text { smithi }\end{array}$ & & $\begin{array}{l}\text { Electrophysiological experiments } \\
\text { with human peripheral T } \\
\text { lymphocytes/ In vivo assay using } \\
\text { DTH reaction, Lewis rats }\end{array}$ & 0.0029 & [33] \\
\hline
\end{tabular}

* Selectivity for Kv1.3 channels (toxins unknown action on other channels)

\# Presented in vivo assays

$\mathrm{EC}_{50}$ : half maximal effective concentration

$\mathrm{IC}_{50}$ : half maximal inhibitory concentration

$\mathrm{K}_{\mathrm{d}}$ : dissociation constant

ND: not-determined

\section{Kv1.3 channels and their therapeutic implications}

After presenting an in-depth view regarding Kv1.3 channel structure, function and mechanism on the immunological system, along with a list of all known scorpion toxins targeting this channel, this section will demonstrate channel effectiveness as a therapeutic approach. Although many scorpion toxins presented selective capacity to block Kvl.3 channels, most of them were only evaluated using in vitro tests (e.g. voltage clamp with two microelectrodes, patch-clamp, etc). Therefore, even though they can be classified as a potential candidate to therapeutic use, no evidence was reported in vivo and/or in humans. Thence, these toxins will not constitute the focus of this discussion. Below are presented few examples and a discussion supporting scorpion toxins that block Kv1.3 channel and present proof of concept in vivo.

An association was established between the expression of potassium channels, the proliferation and survival of oncotic cells. Nevertheless, it is not clear if these channels can participate in the angiogenic stimulation, checkpoint approval during mitosis or other mechanisms involved. Even though, it was observed that Kv1.3 channels overexpression leads to tumoral cell growth. Based on that, a trial facing A549 cell line (human lung adenocarcinoma) in vitro using margatoxin (toxin from Centruroides margaritatus scorpion venom) was done, resulting in suppression of lung carcinoma, achieving a significant blockage of the tumor grown and even a reduction on its volume. Another approach applied margatoxin into a xenograft model using nude mice and the toxin caused a reduction of tumor volume when it was injected into the tumor tissues [135, 136, 153].

A very promising toxin is OsK1 from Orthochirus scrobiculosus scorpion venom, more specially its synthesizable mutated form, which allows to improve its characteristic of being more specific to Kv1.3 than to Kv1.1 and 1.2 channels. The toxin has been tested in vitro upon L929 and murine erythroleukaemia (MEL) cells stably expressing mouse Kv1.3 (mKv1.3), Kv3.1 (mKv3.1), human Kv1.5 (hKv1.5) channels and COS7 cells, as well as using in vivo assays in C57/BL6 mice. These assays demonstrated a high inhibitory effect of the peptide and its analogues on Kv1.3 channels. Therefore, due to the inborn potential and the possibility of versatile analogues, OsK1 is considered an important peptide for the development of immunosuppressive drugs [143].

Knowing that Kv1.3 channel holds an essential role to regulate ions and function of immunological cells, theoretically, any peptide capable of suppressing the Kv1.3 channel is a potential therapeutic option for diseases that require immunosuppression. Thus, different trials have been conducted to define if the suppression of this channel could lead to selective immunosuppression resulting in benefits to a patient with autoimmune inflammatory diseases [18, 33, 149, 154, 155].

Tests with ImKTx88 (from Isometrus masculatus scorpion venom) were conducted with mice model of EAE to evaluate the toxin efficacy to prevent the blood-brain barrier disruption and subsequent infiltration of auto-reactive lymphocytes. This peptide was able to improve the severity of the disease and stabilize the barrier by selectively blocking Kv1.3 channels, leading to changes in expressions of adhesion molecules, receptors and interleukins. 
This effect is known as a recommendation of a possible therapy to multiple sclerosis $[127,156]$.

HsTX1 and its analogs, PEG-HsTX1[R14A] and HsTX1[R14A] were able to reduce inflammation in an active DTH model (Lewis rats) and in the pristine-induced arthritis rat model (Dark Agouti rats) [124].

Likewise, peptide Vm24, from Vaejovis mexicanus smithi scorpion venom, in murine models (female Lewis rats), was able to reduce the DTH reaction. Further studies showed the high affinity of the toxin with human lymphocytes, suggesting new experiments to determine possible clinical application [33, 157].

Kaliotoxin (from Androctonus mauretanicus mauretanicus scorpion venom) was able to decrease T-cell activation, leading to a decreased bone resorption when facing experimental periodontal disease in rat models. Thus, this toxin works as a factor of bone protection, being considered a potential therapeutic drug to prevent alveolar bone loss in humans [129, 158, 159].

Charybdotoxin (from Leiurus quinquestriatus hebraeus scorpion venom) suppressed lymphocyte proliferation and interleukin-2 (IL-2) production in both human and mice lymphocytes. However, because it is considered as a lessselective inhibitor, it can cause adverse effects, such as decrease in prothrombinase activity as well as exposure of phosphatidylserine (an outer surface membrane aggregating factor), leading to predisposition to hemorrhage due to the consumption of coagulation factors [16, 158, 160, 161].

Ts6 and Ts15 toxins (from Tityus serrulatus scorpion venom) demonstrated suppressive effects on DTH in BALB/c mice paw tissue $24 \mathrm{~h}$ post-toxin challenge. DTH is a reaction mediated predominantly by skin-homing $\mathrm{T}_{\mathrm{EM}} \mathrm{CD}^{+}$. Therefore, the study indicates that these toxins could be promising candidates for autoimmune disease therapy [148].

\section{Concluding remarks}

The Kv1.3 channels had already proved their potential as a therapeutic target to treat diseases, such as cancer and autoimmune diseases. Since Kv1.3 regulates calcium signaling inside $\mathrm{T}_{\mathrm{EM}}$ cells, which were considered the major actors in mediating chronic autoimmune response, molecules that present selectivity and high affinity to this channel could be used to design novel immunosuppressive drugs. A new medicine discovered from single venom could be seen as a gift by nature. Scorpion toxins are known to be a great source of neurotoxins including Kv1.3 blockers. With 68 promising Kv1.3 toxins' blockers so far, it is evident that new immunosuppressive therapeutic drugs can be obtained by scorpion venoms. However, these molecules still need to be structurally improved (e.g. chemical modifications to improve selectivity and reduce immunogenicity) before reach the market, besides further in vivo and clinical studies.

\section{Abbreviations}

ATP: adenosine triphosphate; $\mathrm{Ca}^{2+}$ : calcium; CD25: interleukin-2 receptor alpha chain; CNS: central nervous system; CRAC: calcium-release-activated-calcium channel; CTLA4: cytotoxic T-lymphocyte-associated protein 4; DTH: delayed-type hypersensitivity; EAE: experimental autoimmune encephalomyelitis; FoxO1: forkhead box protein O1; GATA1: erythroid transcription factor; GYGD: glycine-tyrosine-glycineaspartic acid; IL-2: interleukin-2; IL-10: interleukin-10; InsP3R: inositol-1,4,5-trisphosphate receptor; $\mathrm{KCa}$ : potassium channel activated by calcium; KTx: potassium channel acting toxins; Kv: voltage-gated potassium channels; Kvl: voltage-gated potassium channel type 1; Kv1.3: voltage-gated potassium channel type $1.3 ; \mathrm{K}^{+}$: potassium; $\mathrm{MCU}$ : mitochondrial $\mathrm{Ca}^{2+}$ uniporter; $\mathrm{NK}$ : natural killer; PSD-95: postsynaptic density protein 95; PMCA: plasma membrane $\mathrm{Ca}^{2+}$ ATPase; pSTAT5: phosphospecific signal transducer and activator of transcription 5; SERCA: sarco/endoplasmatic reticulum $\mathrm{Ca}^{2+}$ ATPase; $\mathrm{T}_{\mathrm{CM}}$ : central memory $\mathrm{T}$ cells; $\mathrm{T}_{\mathrm{EM}}$ : $\mathrm{T}$-effector memory lymphocytes; TrKB: Tropomyosin receptor kinase $\mathrm{B} ; \mathrm{T}_{\mathrm{RM}}$ : tissue resident memory $\mathrm{T}$ cells; $\mathrm{T}_{\mathrm{SCM}}$ : stem memory $\mathrm{T}$ cells.

\section{Availability of data and material}

Not applicable.

\section{Funding}

Financial support of Fundação de Amparo à Pesquisa do Estado de São Paulo (FAPESP), São Paulo Research Foundation, scholarships to ISO n. 2017/03580-9 and n.2018/21233-7, and FAC n. 2017/14035-1 and 2018/14158-9). Also, this work was supported in part by Coordenação de Aperfeiçoamento de Pessoal de Nível Superior (CAPES, Coordination for the Improvement of Higher Education Personnel) through Programa Editoração CAPES (call n. 13/2016, grant n. 0722/2017, record n. 88881.142062/2017-01) and by Conselho Nacional de Desenvolvimento Científico e Tecnológico (CNPq, The National Council for Scientific and Technological Development) through Programa Editorial CNPq/CAPES (call n. 26/2017, grant n. 440954/2017-7 and call n.18/2018 grant n. 404770/2018-5) and Produtividade em Desenvolvimento Tecnológico e Extensão Inovadora (scholarship to MBP, n.307155/2017-0).

\section{Competing interests}

Not applicable.

\section{Authors' contributions}

IGB, GMA, FAC, CMC, ECA and UZ wrote part of the review and provided critical feedback. ISO presented the major contribution (took the lead in writing the manuscript). MBP is the corresponding author and designer of the review. All authors read and approved the final manuscript.

\section{Ethics approval and consent to participate}

Not applicable.

\section{Consent for publication}

Not applicable. 


\section{References}

1. Lima M, Pimenta A, Martin-Eauclaire M, Zingali R, Rochat H. Animal toxins: State of the art - perspectives in Health and Biotechnology. J Venom Anim Toxins incl Trop Dis. 2009;15(3). doi: dx.doi.org/10.1590/ S1678-91992009000300021.

2. Peigneur S, Tytgat J. Toxins in drug discovery and pharmacology. Toxins (Basel). 2018;10(3):pii: E126.

3. de Souza JM, Goncalves BDC, Gomez MV, Vieira LB, Ribeiro FM. Animal toxins as therapeutic tools to treat neurodegenerative diseases. Front Pharmacol. 2018;9:145.

4. Casewell NR, Wuster W, Vonk FJ, Harrison RA, Fry BG. Complex cocktails: the evolutionary novelty of venoms. Trends Ecol Evol. 2013;28(4):219-29.

5. Biscola NP, Cartarozzi LP, Ulian-Benitez S, Barbizan R, Castro MV, Spejo $A B$, et al. Multiple uses of fibrin sealant for nervous system treatment following injury and disease. J Venom Anim Toxins incl Trop Dis. 2017;23:13. doi: 10.1186/s40409-017-0103-1.

6. Ferreira RS Jr, de Barros LC, Abbade LPF, Barraviera SRCS, Silvares $M R C$, de Pontes LG, et al. Heterologous fibrin sealant derived from snake venom: from bench to bedside - an overview. J Venom Anim Toxins incl Trop Dis. 2017;23:21. doi: 10.1186/s40409-017-0109-8.

7. Takacs Z, Nathan S. Animal venoms in medicine. In Encyclopedia of Toxicology. $3^{\text {a }}$ edition. Wexler P editor. Academic Press; 2014. p. 252-9.

8. da Mata ECG, Mourão CBF, Rangel M, Schwartz EF. Antiviral activity of animal venom peptides and related compounds. J Venom Anim Toxins incl Trop Dis. 2017;23:3. doi: 10.1186/s40409-016-0089-0.

9. Pucca MB, Cerni FA, Pinheiro Junior EL, Bordon Kde C, Amorim FG, Cordeiro FA, et al. Tityus serrulatus venom - a lethal cocktail. Toxicon. 2015;108:272-84.

10. Nencioni ALA, Neto EB, de Freitas LA, Dorce VAC. Effects of Brazilian scorpion venoms on the central nervous system. J Venom Anim Toxins incl Trop Dis. 2018;24:3. doi: 10.1186/s40409-018-0139-x.

11. Casella-Martins A, Ayres LR, Burin SM, Morais FR, Pereira JC, Faccioli LH, et al. Immunomodulatory activity of Tityus serrulatus scorpion venom on human T lymphocytes. J Venom Anim Toxins incl Trop Dis. 2015;21:46.

12. Ye F, Hu Y, Yu W, Xie Z, Hu J, Cao Z, et al. The scorpion toxin analogue BmKTX-D33H as a potential Kv1.3 channel-selective immunomodulator for autoimmune diseases. Toxins (Basel). 2016;8(4):115.

13. Bordon KCF, Cologna CT, Arantes EC. Scorpion Venom Research Around the World: Tityus serrulatus. In: Scorpion Venoms. Gopalakrishnakone P, Possani LD, Schwartz EF, de la Vega RCR editors. Volume 4. Netherlands: Springer; 2015. p. 411-37.

14. Kuzmenkov AI, Grishin EV, Vassilevski AA. Diversity of potassium channel ligands: focus on scorpion toxins. Biochemistry (Mosc). 2015;80(13):1764-99.

15. Wickenden AD. K(+) channels as therapeutic drug targets. Pharmacol Ther. 2002;94(1-2):157-82.

16. Beeton C, Pennington MW, Wulff H, Singh S, Nugent D, Crossley G, et al. Targeting effector memory $T$ cells with a selective peptide inhibitor of Kv1.3 channels for therapy of autoimmune diseases. Mol Pharmacol. 2005;67(4):1369-81.

17. Zhao Y, Huang J, Yuan X, Peng B, Liu W, Han S, et al. Toxins targeting the Kv1.3 channel: potential immunomodulators for autoimmune diseases. Toxins (Basel). 2015;7(5):1749-64.

18. Beeton $\mathrm{C}$, Wulff $\mathrm{H}$, Standifer NE, Azam P, Mullen KM, Pennington MW, et al. Kv1.3 channels are a therapeutic target for T cell-mediated autoimmune diseases. Proc Natl Acad Sci U S A. 2006;103(46):17414-9.

19. Prentis PJ, Pavasovic A, Norton RS. Sea anemones: quiet achievers in the field of peptide toxins. Toxins (Basel). 2018;10(1):pii: E36.

20. Tarcha EJ, Chi V, Munoz-Elias EJ, Bailey D, Londono LM, Upadhyay SK, et al. Durable pharmacological responses from the peptide ShK-186, a specific Kv1.3 channel inhibitor that suppresses T cell mediators of autoimmune disease. J Pharmacol Exp Ther. 2012;342(3):642-53.

21. Norton RS, Chandy KG. Venom-derived peptide inhibitors of voltagegated potassium channels. Neuropharmacology. 2017;127:124-38.
22. Chandy KG, Norton RS. Peptide blockers of Kv1.3 channels in T cells as therapeutics for autoimmune disease. Curr Opin Chem Biol. 2017;38:97-107.

23. Matteson DR, Deutsch C. K channels in T lymphocytes: a patch clamp study using monoclonal antibody adhesion. Nature. 1984;307(5950):46871.

24. Cahalan MD, Chandy KG, DeCoursey TE, Gupta S. A voltage-gated potassium channel in human T lymphocytes. J Physiol. 1985;358:197-237.

25. Gutman GA, Chandy KG, Grissmer S, Lazdunski M, Mckinnon D, Pardo LA, et al. International Union of Pharmacology. LIII. Nomenclature and molecular relationships of voltage-gated potassium channels. Pharmacol Rev. 2005;57(4):473-508.

26. Teisseyre A, Gasiorowska J, Michalak K. Voltage-gated potassium channels Kv1.3 - potentially new molecular target in cancer diagnostics and therapy. Adv Clin Exp Med. 2015;24(3):517-24.

27. O'Grady SM, Lee SY. Molecular diversity and function of voltage-gated (Kv) potassium channels in epithelial cells. Int J Biochem Cell Biol. 2005;37(8):1578-94.

28. Chandy KG, Strong M, Aiyar J, Gutman GA. Structural and biochemical features of the Kv1.3 potassium channel: an aid to guided drug design. Cell Physiol Biochem. 1997;7:135-47.

29. Choe S. Potassium channel structures. Nat Rev Neurosci. 2002;3(2):11521.

30. Aiyar J, Rizzi JP, Gutman GA, Chandy KG. The signature sequence of voltage-gated potassium channels projects into the external vestibule. J Biol Chem. 1996;271(49):31013-6.

31. Aiyar J, Withka JM, Rizzi JP, Singleton DH, Andrews GC, Lin W, et al. Topology of the pore-region of a $\mathrm{K}+$ channel revealed by the NMRderived structures of scorpion toxins. Neuron. 1995;15(5):1169-81.

32. Chen R, Robinson A, Gordon D, Chung SH. Modeling the binding of three toxins to the voltage-gated potassium channel (Kv1.3). Biophys J. 2011;101(11):2652-60.

33. Varga Z, Gurrola-Briones G, Papp F, Rodriguez de la Vega RC, PedrazaAlva G, Tajhya RB, et al. Vm24, a natural immunosuppressive peptide, potently and selectively blocks Kv1.3 potassium channels of human T cells. Mol Pharmacol. 2012;82(3):372-82.

34. Cerni FA, Pucca MB, Peigneur S, Cremonez CM, Bordon KC, Tytgat J, et al. Electrophysiological characterization of Ts 6 and Ts7, $\mathrm{K}^{+}$channel toxins isolated through an improved Tityus serrulatus venom purification procedure. Toxins (Basel). 2014;6(3):892-913.

35. Lewis RS, Cahalan MD. Potassium and calcium channels in lymphocytes. Annu Rev Immunol. 1995;13:623-53.

36. Kotecha SA, Schlichter LC. A Kv1.5 to Kv1.3 switch in endogenous hippocampal microglia and a role in proliferation. J Neurosci. 1999;19(24):10680-93.

37. Cayabyab FS, Khanna R, Jones OT, Schlichter LC. Suppression of the rat microglia Kv1.3 current by src-family tyrosine kinases and oxygen/ glucose deprivation. Eur J Neurosci. 2000;12(6):1949-60.

38. Wulff H, Castle NA, Pardo LA. Voltage-gated potassium channels as therapeutic targets. Nat Rev Drug Discov. 2009;8(12):982-1001.

39. Serrano-Albarrás A, Estadella I, Cirera-Rocosa S, Navarro-Pérez M, Felipe A. Kv1.3: a multifunctional channel with many pathological implications. Expert Opin Ther Targets. 2018;22(2):101-5.

40. Zweifach A, Lewis RS. Mitogen-regulated Ca2+ current of T lymphocytes is activated by depletion of intracellular $\mathrm{Ca} 2+$ stores. Proc Natl Acad Sci U S A. 1993;90(13):6295-9.

41. Wulff H, Calabresi PA, Allie R, Yun S, Pennington M, Beeton C, et al. The voltage-gated $\mathrm{Kv} 1.3 \mathrm{~K}(+)$ channel in effector memory $\mathrm{T}$ cells as new target for MS. J Clin Invest. 2003;111(11):1703-13.

42. Hu L, Pennington M, Jiang Q, Whartenby KA, Calabresi PA. Characterization of the functional properties of the voltage-gated potassium channel Kv1.3 in human CD4+ T lymphocytes. J Immunol. 2007;179(7):4563-70.

43. Hu L, Gocke AR, Knapp E, Rosenzweig JM, Grishkan IV, Baxi EG, et al. Functional blockade of the voltage-gated potassium channel Kv1.3 mediates reversion of $\mathrm{T}$ effector to central memory lymphocytes through SMAD3/p21cip1 signaling. J Biol Chem. 2012;287(2):1261-8. 
44. Cahalan MD, Chandy KG. The functional network of ion channels in $\mathrm{T}$ lymphocytes. Immunol Rev. 2009;231(1):59-87.

45. Duque A, Gazula VR, Kaczmarek LK. Expression of Kv1.3 potassium channels regulates density of cortical interneurons. Dev Neurobiol. 2013;73(11):841-55.

46. Marom S, Levitan IB. State-dependent inactivation of the Kv3 potassium channel. Biophys J. 1994;67(2):579-89.

47. Nicolaou SA, Neumeier L, Steckly A, Kucher V, Takimoto K, Conforti L. Localization of Kv1.3 channels in the immunological synapse modulates the calcium response to antigen stimulation in T lymphocytes. J Immunol. 2009;183(10):6296-302.

48. Fadool DA, Tucker K, Perkins R, Fasciani G, Thompson RN, Parsons $A D$, et al. Kv1.3 channel gene-targeted deletion produces "SuperSmeller Mice" with altered glomeruli, interacting scaffolding proteins, and biophysics. Neuron. 2004:41(3):389-404.

49. Gocke AR, Lebson LA, Grishkan IV, Hu L, Nguyen HM, Whartenby $\mathrm{KA}$, et al. Kv1.3 deletion biases $\mathrm{T}$ cells toward an immunoregulatory phenotype and renders mice resistant to autoimmune encephalomyelitis. J Immunol. 2012;188(12):5877-86.

50. Grishkan IV, Tosi DM, Bowman MD, Harary M, Calabresi PA, Gocke AR. Antigenic stimulation of Kv1.3-deficient Th cells gives rise to a population of Foxp3-Independent T cells with suppressive properties. J Immunol. 2015;195(4):1399-407.

51. Chiang EY, Li T, Jeet S, Peng I, Zhang J, Lee WP, et al. Potassium channels Kv1.3 and KCa3.1 cooperatively and compensatorily regulate antigen-specific memory T cell functions. Nat Commun. 2017;8:14644.

52. Tucker K, Overton JM, Fadool DA. Diet-induced obesity resistance of Kv1.3-/- mice is olfactory bulb dependent. J Neuroendocrinol. 2012;24(8):1087-95.

53. Xu J, Koni PA, Wang P, Li G, Kaczmarek L, Wu Y, et al. The voltagegated potassium channel Kv1.3 regulates energy homeostasis and body weight. Hum Mol Genet. 2003;12(5):551-9.

54. Tucker K, Cavallin MA, Jean-Baptiste P, Biju KC, Overton JM, Pedarzani $P$, et al. The olfactory bulb: a metabolic sensor of brain insulin and glucose concentrations via a voltage-gated potassium channel. Results Probl Cell Differ. 2010;52:147-57.

55. Huang Z, Hoffman CA, Chelette BM, Thiebaud N, Fadool DA. Elevated anxiety and impaired attention in super-smeller, Kv1.3 knockout mice. Front Behav Neurosci. 2018;12:49.

56. Koni PA, Khanna R, Chang MC, Tang MD, Kaczmarek LK, Schlichter LC, et al. Compensatory anion currents in Kv1.3 channel-deficient thymocytes. J Biol Chem. 2003;278:39443-51.

57. Vaeth $M$, Feske S. Ion channelopathies of the immune system. Curr Opin Immunol. 2018;52:39-50.

58. Kim JB. Channelopathies. Korean J Pediatr. 2014;57(1):1-18.

59. Grabbe S, Schwarz T. Immunoregulatory mechanisms involved in elicitation of allergic contact hypersensitivity. Immunol Today. 1998;19(1):37-44.

60. Petukhova L, Duvic M, Hordinsky M, Norris D, Price V, Shimomura Y, et al. Genome-wide association study in alopecia areata implicates both innate and adaptive immunity. Nature. 2010;466:113-7.

61. Gilhar A, Landau M, Assy B, Ullmann Y, Shalaginov R, Serafimovich S, et al. Transfer of alopecia areata in the human scalp graft/Prkdc(scid) (SCID) mouse system is characterized by a $\mathrm{TH} 1$ response. Clin Immunol. 2003;106(3):181-7.

62. Gilhar A, Shalaginov R, Assy B, Serafimovich S, Kalish RS. Alopecia areata is a T-lymphocyte mediated autoimmune disease: lesional human T-lymphocytes transfer alopecia areata to human skin grafts on SCID mice. J Investig Dermatol Symp Proc. 1999;4(3):207-10.

63. Tian B, Patrikeev I, Ochoa L, Vargas G, Belanger KK, Litvinov J, et al. NF- $\kappa B$ mediates mesenchymal transition, remodeling, and pulmonary fibrosis in response to chronic inflammation by viral RNA patterns. Am J Respir Cell Mol Biol. 2017;56(4):506-20.

64. Frieri M, Stampfl H. Systemic lupus erythematosus and atherosclerosis: review of the literature. Autoimmun Rev. 2016;15(1):16-21.
65. DeSantis CE, Ma J, Goding Sauer A, Newman LA, Jemal A. Breast cancer statistics, 2017, racial disparity in mortality by state. CA Cancer J Clin. 2017;67(6):439-48.

66. Hallek M. Chronic lymphocytic leukemia: 2015 update on diagnosis, risk stratification, and treatment. Am J Hematol. 2015;90(5):446-60.

67. Rozman C, Montserrat E. Chronic lymphocytic leukemia. N Engl J Med. 1995;333(16):1052-7.

68. Marinho AWGB, Penha AP, Silva MT, Galvão TF. Prevalência de doença renal crônica em adultos no Brasil: revisão sistemática da literatura. Cad Saúde Colet. 2017;25(3):379-88.

69. Friedman MG, Bryen DN. Web accessibility design recommendations for people with cognitive disabilities. Technol Disabil. 2007;19(4):205-12.

70. Cho JH, Fu Y, Kirschner BS, Hanauer SB. Confirmation of a susceptibility locus for Crohn' disease on chromosome 16. Inflamm Bowel Dis. 1997;3(3):186-90.

71. Lovett-Racke AE, Trotter JL, Lauber J, Perrin PJ, June CH, Racke MK. Decreased dependence of myelin basic protein-reactive $T$ cells on CD28-mediated costimulation in multiple sclerosis patients. A marker of activated/memory T cells. J Clin Invest. 1998;101(4):725-30.

72. Bielanska J, Hernández-Losa J, Moline T, Somoza R, Ramón y Cajal S, Condom E, et al. Differential expression of Kv1.3 and Kv1.5 voltagedependent $\mathrm{K}+$ channels in human skeletal muscle sarcomas. Cancer Invest. 2012;30(3):203-8.

73. Bernardi F, Cichelero C, Vitolo MR. Comportamento de restrição alimentar e obesidade. Rev Nutr. 2005;18(1):85-93.

74. Varambally S, Dhanasekaran SM, Zhou M, Barrette TR, Kumar-Sinha C, Sanda MG, et al. The polycomb group protein EZH2 is involved in progression of prostate cancer. Nature. 2002;419(6907):624-9.

75. Christophers E. Psoriasis--epidemiology and clinical spectrum. Clin Exp Dermatol. 2001;26(4):314-20.

76. Anderson KO, Bradley LA, Young LD, McDaniel LK, Wise CM. Rheumatoid arthritis: review of psychological factors related to etiology, effects, and treatment. Psychol Bull. 1985;98(2):358-87.

77. Viglietta $\bigvee$, Kent SC, Orban T, Hafler DA. GAD65-reactive T cells are activated in patients with autoimmune type 1a diabetes. J Clin Invest. 2002;109(7):895-903.

78. van den Ouweland JM, Lemkes $\mathrm{HH}$, Ruitenbeek W, Sandkuijl LA, de Vijlder MF, Struyvenberg PA, et al. Mutation in mitochondrial tRNA(Leu) (UUR) gene in a large pedigree with maternally transmitted type II diabetes mellitus and deafness. Nat Genet. 1992;1(5):368-71.

79. Lie JT. Diagnostic histopathology of major systemic and pulmonary vasculitic syndromes. Rheum Dis Clin North Am. 1990;16(2):269-92.

80. Feske S. Calcium signalling in lymphocyte activation and disease. Nat Rev Immunol. 2007;7(9):690-702.

81. Timmerman LA, Clipstone NA, Ho SN, Northrop JP, Crabtree GR. Rapid shuttling of NF-AT in discrimination of $\mathrm{Ca} 2+$ signals and immunosuppression. Nature. 1996;383(6603):837-40.

82. Lam J, Wulff H. The lymphocyte potassium channels Kv1.3 and KCa3.1 as targets for immunosuppression. Drug Dev Res. 2011;72(7):573-84.

83. Le Deist F, Hivroz C, Partiseti M, Thomas C, Buc HA, Oleastro M, et al. A primary T-cell immunodeficiency associated with defective transmembrane calcium influx. Blood. 1995;85(4):1053-62.

84. Feske S, Prakriya M, Rao A, Lewis RS. A severe defect in CRAC $\mathrm{Ca}^{2+}$ channel activation and altered $\mathrm{K}^{+}$channel gating in $\mathrm{T}$ cells from immunodeficient patients. J Exp Med. 2005;202(5):651-62.

85. Farber DL, Yudanin NA, Restifo NP. Human memory T cells: generation, compartmentalization and homeostasis. Nat Rev Immunol. 2014;14(1):2435.

86. Ghanshani S, Wulff H, Miller MJ, Rohm H, Neben A, Gutman GA, et al. Up-regulation of the IKCa1 potassium channel during T-cell activation. Molecular mechanism and functional consequences. J Biol Chem. 2000;275(47):37137-49.

87. Beeton C, Chandy KG. Potassium channels, memory T cells, and multiple sclerosis. Neuroscientist. 2005;11(6):550-62.

88. Dolmetsch RE, Xu K, Lewis RS. Calcium oscillations increase the efficiency and specificity of gene expression. Nature. 1998;392:933-6. 
89. Koo GC, Blake JT, Talento A, Nguyen M, Lin S, Sirotina A, et al. Blockade of the voltage-gated potassium channel Kv1.3 inhibits immune responses in vivo. J Immunol. 1997;158(11):5120-8.

90. Beeton C, Wulff H, Barbaria J, Clot-Faybesse O, Pennington M, Bernard $D$, et al. Selective blockade of T lymphocyte $K(+)$ channels ameliorates experimental autoimmune encephalomyelitis, a model for multiple sclerosis. Proc Natl Acad Sci U S A. 2001;98(24):13942-7.

91. Jiménez-Vargas JM, Possani LD, Luna-Ramírez K. Arthropod toxins acting on neuronal potassium channels. Neuropharmacology. 2017;127:139-60.

92. Rodríguez de la Vega RC, Possani LD. Current views on scorpion toxins specific for K+-channels. Toxicon. 2004;43(8):865-75.

93. Cremonez CM, Maiti M, Peigneur S, Cassoli JS, Dutra AA, Waelkens $E$, et al. Structural and functional elucidation of peptide Ts11 shows evidence of a novel subfamily of scorpion venom toxins. Toxins (Basel). 2016;8(10):pii: E288.

94. Tytgat J, Chandy KG, Garcia ML, Gutman GA, Martin-Eauclaire MF, van der Walt JJ, et al. A unified nomenclature for short-chain peptides isolated from scorpion venoms: alpha-KTx molecular subfamilies. Trends Pharmacol Sci. 1999;20(11):444-7.

95. Kuzmenkov Al, Krylov NA, Chugunov AO, Grishin EV, Vassilevski AA. Kalium: a database of potassium channel toxins from scorpion venom. Database (Oxford). 2016;2016.

96. Norton RS, Pennington MW, Wulff H. Potassium channel blockade by the sea anemone toxin ShK for the treatment of multiple sclerosis and other autoimmune diseases. Curr Med Chem. 2004;11(23):3041-52.

97. Abbas N, Belghazi M, Abdel-Mottaleb Y, Tytgat J, Bougis PE, MartinEauclaire MF. A new Kaliotoxin selective towards Kv1.3 and Kv1.2 but not Kv1.1 channels expressed in oocytes. Biochem Biophys Res Commun. 2008;376(3):525-30.

98. Han S, Yi H, Yin SJ, Chen ZY, Liu H, Cao ZJ, et al. Structural basis of a potent peptide inhibitor designed for Kv1.3 channel, a therapeutic target of autoimmune disease. J Biol Chem. 2008;283(27):19058-65.

99. Garcia ML, Garcia-Calvo M, Hidalgo P, Lee A, MacKinnon R. Purification and characterization of three inhibitors of voltage-dependent $\mathrm{K}^{+}$channels from Leiurus quinquestriatus var. hebraeus venom. Biochemistry. 1994;33(22):6834-9.

100. Anangi R, Koshy S, Huq R, Beeton C, Chuang WJ, King GF. Recombinant expression of margatoxin and agitoxin-2 in Pichia pastoris: an efficient method for production of KV1.3 channel blockers. PLoS One. 2012;7(12):e52965.

101. Bagdány M, Batista CV, Valdez-Cruz NA, Somodi S, Rodriguez de la Vega RC, Licea AF, et al. Anuroctoxin, a new scorpion toxin of the alpha-KTx 6 subfamily, is highly selective for Kv1.3 over IKCa1 ion channels of human T lymphocytes. Mol Pharmacol. 2005;67(4):1034-44.

102. Mao X, Cao Z, Yin S, Ma Y, Wu Y, Li W. Cloning and characterization of BmK86, a novel K+ -channel blocker from scorpion venom. Biochem Biophys Res Commun. 2007;360(4):728-34.

103. Chen ZY, Hu YT, Yang WS, He YW, Feng J, Wang B, et al. Hg1, novel peptide inhibitor specific for Kv1.3 channels from first scorpion kunitztype potassium channel toxin family. J Biol Chem. 2012;287(17):13813-21.

104. Chen Z, Hu Y, Hu J, Yang W, Sabatier JM, De Waard M, et al. Unusual binding mode of scorpion toxin BmKTX onto potassium channels relies on its distribution of acidic residues. Biochem Biophys Res Commun. 2014;447(1):70-6.

105. Zhu S, Peigneur S, Gao B, Luo L, Jin D, Zhao Y, et al. Molecular diversity and functional evolution of scorpion potassium channel toxins. Mol Cell Proteomics. 2011;10(2):M110.002832.

106. Zhu L, Gao B, Luo L, Zhu S. Two dyad-free Shaker-type $\mathrm{K}^{+}$channel blockers from scorpion venom. Toxicon. 2012;59(3):402-7.

107. Romi-Lebrun R, Lebrun B, Martin-Eauclaire MF, Ishiguro M, Escoubas $\mathrm{P}, \mathrm{Wu} \mathrm{FQ}$, et al. Purification, characterization, and synthesis of three novel toxins from the Chinese scorpion Buthus martensi, which act on K+ channels. Biochemistry. 1997;36(44):13473-82.

108. Kozminsky-Atias A, Somech E, Zilberberg N. Isolation of the first toxin from the scorpion Buthus occitanus israelis showing preference for Shaker potassium channels. FEBS Lett. 2007;581(13):2478-84.
109. Coronas FV, de Roodt AR, Portugal TO, Zamudio FZ, Batista CV, Gómez-Lagunas F, Possani LD. Disulfide bridges and blockage of Shaker B K(+)-channels by another butantoxin peptide purified from the Argentinean scorpion Tityus trivittatus. Toxicon. 2003;41(2):173-9.

110. Pimenta AM, Mansuelle P, Diniz CR, Martin-Eauclaire MF. Covalent structure and some pharmacological features of native and cleaved alpha-KTx12-1, a four disulfide-bridged toxin from Tityus serrulatus venom. J Pept Sci. 2003;9(2):132-40.

111. Olamendi-Portugal T, Somodi S, Fernández JA, Zamudio FZ, Becerril $B$, Varga Z, et al. Novel alpha-KTx peptides from the venom of the scorpion Centruroides elegans selectively blockade Kv1.3 over IKCa1 $\mathrm{K}+$ channels of T cells. Toxicon. 2005;46(4):418-29.

112. Grissmer S, Nguyen AN, Aiyar J, Hanson DC, Mather RJ, Gutman GA, et al. Pharmacological characterization of five cloned voltage-gated $\mathrm{K}+$ channels, types $\mathrm{Kv1.1}, 1.2,1.3,1.5$, and 3.1 , stably expressed in mammalian cell lines. Mol Pharmacol. 1994;45(6):1227-34.

113. Jouirou B, Mosbah A, Visan V, Grissmer S, M'Barek S, Fajloun Z, et al. Cobatoxin 1 from Centruroides noxius scorpion venom: chemical synthesis, three-dimensional structure in solution, pharmacology and docking on K+ channels. Biochem J. 2004;377(Pt 1):37-49.

114. Corzo G, Papp F, Varga Z, Barraza O, Espino-Solis PG, Rodriguez de la Vega RC, et al. A selective blocker of Kv1.2 and Kv1.3 potassium channels from the venom of the scorpion Centruroides suffusus suffusus. Biochem Pharmacol. 2008;76(9):1142-54.

115. Ding L, Chen J, Hao J, Zhang J, Huang X, Hu F, et al. Discovery of three toxin peptides with Kv1.3 channel and IL-2 cytokine-inhibiting activities from Non-Buthidae scorpions, Chaerilus tricostatus and Chaerilus tryznai. Peptides. 2017;91:13-9.

116. Xie S, Feng J, Yu C, Li Z, Wu Y, Cao Z, et al. Identification of a new specific Kv1.3 channel blocker, Ctri9577, from the scorpion Chaerilus tricostatus. Peptides. 2012;36(1):94-9.

117. Srairi-Abid N, Shahbazzadeh D, Chatti I, Mlayah-Bellalouna S, Mejdoub $H$, Borchani $L$, et al. Hemitoxin, the first potassium channel toxin from the venom of the Iranian scorpion Hemiscorpius lepturus. FEBS J. 2008;275(18):4641-50.

118. Hoang AN, Vo HD, Vo NP, Kudryashova KS, Nekrasova OV, Feofanov $\mathrm{AV}$, et al. Vietnamese Heterometrus laoticus scorpion venom: evidence for analgesic and anti-inflammatory activity and isolation of new polypeptide toxin acting on Kv1.3 potassium channel. Toxicon. 2014;77:40-8.

119. Chen ZY, Zeng DY, Hu YT, He YW, Pan N, Ding JP, et al. Structural and functional diversity of acidic scorpion potassium channel toxins. PLoS One. 2012;7(4):e35154.

120. Schwartz EF, Diego-Garcia E, Rodríguez de la Vega RC, Possani LD. Transcriptome analysis of the venom gland of the Mexican scorpion Hadrurus gertschi (Arachnida: Scorpiones). BMC Genomics. 2007;8:119.

121. Zhao R, Dai H, Qiu S, Li T, He Y, Ma Y, et al. SdPI, the first functionally characterized Kunitz-type trypsin inhibitor from scorpion venom. PLoS One. 2011;6(11):e27548.

122. Koschak A, Bugianesi RM, Mitterdorfer J, Kaczorowski GJ, Garcia ML, Knaus HG. Subunit composition of brain voltage-gated potassium channels determined by hongotoxin-1, a novel peptide derived from Centruroides limbatus venom. J Biol Chem. 1998;273(5):2639-44.

123. Regaya I, Beeton C, Ferrat G, Andreotti N, Darbon H, De Waard M, et al. Evidence for domain-specific recognition of SK and Kv channels by MTX and HsTx1 scorpion toxins. J Biol Chem. 2004;279:55690-6.

124. Tanner MR, Tajhya RB, Huq R, Gehrmann EJ, Rodarte KE, Atik MA, et al. Prolonged immunomodulation in inflammatory arthritis using the selective Kv1.3 channel blocker HsTX1[R14A] and its PEGylated analog. Clin Immunol. 2017;180:45-57.

125. Chen Z, Hu Y, Han S, Yin S, He Y, Wu Y, et al. ImKTx1, a new Kv1.3 channel blocker with a unique primary structure. J Biochem Mol Toxicol. 2011;25(4):244-51.

126. Han S, Hu Y, Zhang R, Yi H, Wei J, Wu Y, et al. ImKTx88, a novel selective Kv1.3 channel blocker derived from the scorpion Isometrus maculates. Toxicon. 2011;57(2):348-55. 
127. Huang J, Han S, Sun Q, Zhao Y, Liu J, Yuan X, et al. Kv1.3 channel blocker (ImKTx88) maintains blood-brain barrier in experimental autoimmune encephalomyelitis. Cell Biosci. 2017;7:31.

128. Shijin Y, Hong Y, Yibao M, Zongyun C, Han S, Yingliang W, et al. Characterization of a new Kv1.3 channel-specific blocker, J123, from the scorpion Buthus martensii Karsch. Peptides. 2008;29(9):1514-20.

129. Valverde P, Kawai T, Taubman MA. Selective blockade of voltagegated potassium channels reduces inflammatory bone resorption in experimental periodontal disease. J Bone Miner Res. 2004;19(1):155-64.

130. Mahjoubi-Boubaker B, Crest M, Khalifa RB, El Ayeb M, Kharrat R. Kbot1, a three disulfide bridges toxin from Buthus occitanus tunetanus venom highly active on both SK and Kv channels. Peptides. 2004;25(4):637-45.

131. Srinivasan KN, Sivaraja V, Huys I, Sasaki T, Cheng B, Kumar TK, et al. kappa-Hefutoxin1, a novel toxin from the scorpion Heterometrus fulvipes with unique structure and function. Importance of the functional diad in potassium channel selectivity. J Biol Chem. 2002;277(33):30040-7.

132. Bayrhuber M, Vijayan V, Ferber M, Graf R, Korukottu J, Imperial J, et al. Conkunitzin-S1 is the first member of a new Kunitz-type neurotoxin family. Structural and functional characterization. J Biol Chem. 2005;280(25):23766-70.

133. Liu J, Ma Y, Yin S, Zhao R, Fan S, Hu Y, et al. Molecular cloning and functional identification of a new K(+) channel blocker, LmKTx10, from the scorpion Lychas mucronatus. Peptides. 2009;30(4):675-80.

134. Wu W, Yin S, Ma Y, Wu YL, Zhao R, Gan G, et al. Molecular cloning and electrophysiological studies on the first $\mathrm{K}(+)$ channel toxin (LmKTx8) derived from scorpion Lychas mucronatus. Peptides. 2007;28:2306-12.

135. Garcia-Calvo M, Leonard RJ, Novick J, Stevens SP, Schmalhofer W, Kaczorowski GJ, et al. Purification, characterization, and biosynthesis of margatoxin, a component of Centruroides margaritatus venom that selectively inhibits voltage-dependent potassium channels. J Biol Chem. 1993;268(25):18866-74.

136. Jang SH, Choi SY, Ryu PD, Lee SY. Anti-proliferative effect of Kv1.3 blockers in $\mathrm{A} 549$ human lung adenocarcinoma in vitro and in vivo. Eur J Pharmacol. 2011;651(1-3):26-32.

137. Diego-Garcia E, Peigneur S, Debaveye S, Gheldof E, Tytgat J, Caliskan F. Novel potassium channel blocker venom peptides from Mesobuthus gibbosus (Scorpiones: Buthidae). Toxicon. 2013;61:72-82.

138. Gao B, Peigneur S, Tytgat J, Zhu S. A potent potassium channel blocker from Mesobuthus eupeus scorpion venom. Biochimie. 2010;92(12):184753.

139. Gao B, Peigneur S, Dalziel J, Tytgat J, Zhu S. Molecular divergence of two orthologous scorpion toxins affecting potassium channels. Comp Biochem Physiol A Mol Integr Physiol. 2011;159(3):313-21.

140. Schwartz EF, Bartok A, Schwartz CA, Papp F, Gómez-Lagunas F, Panyi G, et al. OcyKTx2, a new $\mathrm{K}^{+}$-channel toxin characterized from the venom of the scorpion Opisthacanthus cayaporum. Peptides. 2013;46:40-6.

141. Abdel-Mottaleb Y, Vandendriessche T, Clynen E, Landuyt B, Jalali A, Vatanpour $\mathrm{H}$, et al. OdK2, a Kv1.3 channel-selective toxin from the venom of the Iranian scorpion Odonthobuthus doriae. Toxicon. 2008;51(8):1424-30.

142. Chagot B, Pimentel C, Dai L, Pil J, Tytgat J, Nakajima T, et al. An unusual fold for potassium channel blockers: NMR structure of three toxins from the scorpion Opisthacanthus madagascariensis. Biochem J. 2005;388(Pt 1):263-71.

143. Mouhat S, Visan V, Ananthakrishnan S, Wulff H, Andreotti N, Grissmer $\mathrm{S}$, et al. $\mathrm{K}+$ channel types targeted by synthetic OSK1, a toxin from Orthochirus scrobiculosus scorpion venom. Biochem J. 2005;385(Pt 1):95-104.

144. Huys I, Dyason K, Waelkens E, Verdonck F, van Zyl J, du Plessis J, et al. Purification, characterization and biosynthesis of parabutoxin
3, a component of Parabuthus transvaalicus venom. Eur J Biochem. 2002;269(7):1854-65.

145. Péter M, Varga Z, Panyi G, Bene L, Damjanovich S, Pieri C, et al. Pandinus imperator scorpion venom blocks voltage-gated $\mathrm{K}+$ channels in human lymphocytes. Biochem Biophys Res Commun. 1998;242(3):621-5.

146. Batista CV, Gomez-Lagunas F, Rodriguez de la Vega RC, Hajdu P, Panyi G, Gaspar R, et al. Two novel toxins from the Amazonian scorpion Tityus cambridgei that block Kv1.3 and Shaker B K(+)-channels with distinctly different affinities. Biochim Biophys Acta. 2002;1601(2):123-31.

147. Cologna CT, Peigneur S, Rosa JC, Selistre-de-Araujo HS, Varanda WA, Tytgat J, et al. Purification and characterization of Ts15, the first member of a new alpha-KTX subfamily from the venom of the Brazilian scorpion Tityus serrulatus. Toxicon. 2011;58(1):54-61.

148. Pucca MB, Bertolini TB, Cerni FA, Bordon KCF, Peigneur S, Tytgat J, et al. Immunosuppressive evidence of Tityus serrulatus toxins Ts6 and Ts15: insights of a novel $\mathrm{K}(+)$ channel pattern in T cells. Immunology. 2016;147(2):240-50.

149. Papp F, Batista CV, Varga Z, Herceg M, Román-González SA, Gaspar R, et al. Tst26, a novel peptide blocker of Kv1.2 and Kv1.3 channels from the venom of Tityus stigmurus. Toxicon. 2009;54(4):379-89.

150. Abdel-Mottaleb Y, Coronas FV, de Roodt AR, Possani LD, Tytgat J. A novel toxin from the venom of the scorpion Tityus trivittatus, is the first member of a new alpha-KTX subfamily. FEBS Lett. 2006;580(2):592-6.

151. Luna-Ramírez K, Bartok A, Restano-Cassulini R, Quintero-Hernández $\mathrm{V}$, Coronas Fl, Christensen J, et al. Structure, molecular modeling, and function of the novel potassium channel blocker urotoxin isolated from the venom of the Australian scorpion Urodacus yaschenkoi. Mol Pharmacol. 2014;86(1):28-41.

152. Postay LDP, Gurrola-Briones G, Salas-Castillo SP, Ferreira BCV, Varga ZS, Panyi G, et al. Vm23 and Vm24, two scorpion peptides that block human t-lymphocyte potassium channels (sub-type kv1.3) with high selectivity and decrease the in vivo dth-responses in rats. 2007.

153. Becchetti A. lon channels and transporters in cancer. 1. lon channels and cell proliferation in cancer. Am J Physiol Cell Physiol. 2011;301(2):C25565.

154. Feske $\mathrm{S}$, Wulff $\mathrm{H}$, Skolnik EY. Ion channels in innate and adaptive immunity. Annu Rev Immunol. 2015;33:291-353.

155. Rashid MH, Huq R, Tanner MR, Chhabra S, Khoo KK, Estrada R, et al. A potent and Kv1.3-selective analogue of the scorpion toxin HsTX1 as a potential therapeutic for autoimmune diseases. Sci Rep. 2014;4:4509.

156. Han S, Hu Y, Zhang R, Yi H, Wei J, Wu Y, et al. ImKTx88, a novel selective Kv1.3 channel blocker derived from the scorpion Isometrus maculatus. Toxicon. 2011;57(2):348-55.

157. Gurrola GB, Hernández-López RA, Rodríguez de la Vega RC, Varga Z, Batista CV, Salas-Castillo SP, et al. Structure, function, and chemical synthesis of Vaejovis mexicanus peptide 24: a novel potent blocker of Kv1.3 potassium channels of human T lymphocytes. Biochemistry. 2012;51(19):4049-61.

158. Hmed B, Serria HT, Mounir ZK. Scorpion peptides: potential use for new drug development. J Toxicol. 2013;2013:958797.

159. Crest $M$, Jacquet $G$, Gola $M$, Zerrouk $H$, Benslimane $A$, Rochat $H$, et al. Kaliotoxin, a novel peptidyl inhibitor of neuronal BK-type $\mathrm{Ca}(2+)$ activated $\mathrm{K}+$ channels characterized from Androctonus mauretanicus mauretanicus venom. J Biol Chem. 1992;267(3):1640-7.

160. Thell K, Hellinger R, Schabbauer G, Gruber CW. Immunosuppressive peptides and their therapeutic applications. Drug Discov Today. 2014;19(5):645-53.

161. Gimenez-Gallego G, Navia MA, Reuben JP, Katz GM, Kaczorowski GJ, Garcia ML. Purification, sequence, and model structure of charybdotoxin, a potent selective inhibitor of calcium-activated potassium channels. Proc Natl Acad Sci U S A. 1988;85(10):3329-33. 